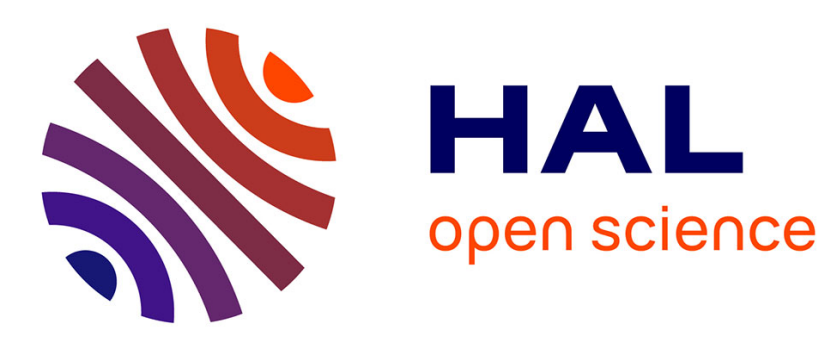

\title{
Corporate Venturing, Allocation of Talent, and Competition for Star Managers
}

\author{
Jean-Etienne de Bettignies, Gilles Chemla
}

\section{To cite this version:}

Jean-Etienne de Bettignies, Gilles Chemla. Corporate Venturing, Allocation of Talent, and Competition for Star Managers. Management Science, 2008, Vol. 54 (Issue n 3), pp. 505-521. halshs00365942

\section{HAL Id: halshs-00365942 \\ https://shs.hal.science/halshs-00365942}

Submitted on 5 Mar 2009

HAL is a multi-disciplinary open access archive for the deposit and dissemination of scientific research documents, whether they are published or not. The documents may come from teaching and research institutions in France or abroad, or from public or private research centers.
L'archive ouverte pluridisciplinaire HAL, est destinée au dépôt et à la diffusion de documents scientifiques de niveau recherche, publiés ou non, émanant des établissements d'enseignement et de recherche français ou étrangers, des laboratoires publics ou privés. 


\title{
Corporate Venturing, Allocation of Talent, and Competition for Star Managers
}

\author{
Jean-Etienne de Bettignies and Gilles Chemla*
}

This Draft: November 20, 2006

\begin{abstract}
We provide new rationales for corporate venturing (CV), based on competition for talented managers. As returns to venturing increase, firms engage in $\mathrm{CV}$ for reasons other than capturing these returns. First, higher venturing returns increase managerial compensation, to which firms respond by increasing the power of incentives. Managers increase effort, prompting firms to reallocate them to new ventures, where the marginal product of effort is highest. Second, as returns to venturing become large, CV emerges as a way to recruit/retain managers who would otherwise choose alternative employment. We derive several testable empirical predictions about the determinants and structure of CV. (JEL Codes: G24, G32, M13, M12)
\end{abstract}

Keywords: Corporate venturing, corporation, venture capitalist, star, effort, competition.

\footnotetext{
*de Bettignies: Sauder School of Business, University of British Columbia, Vancouver BC V6T 1Z2, Canada. Phone: 1604822 8481, fax: 1604822 8477, e-mail: bettignies@sauder.ubc.ca. Chemla: Imperial College London, DRM-CNRS; and CEPR. Tel: 44207594 9161, fax: 44207594 9189; e-mail: g.chemla@imperial.ac.uk. We thank an anonymous referee, the Associate Editor, and the Department Editor David Hsieh, for very insightful suggestions and advice. We also thank Jim Brander, Avi Goldfarb, Thomas Hellmann, John Ries, Tom Ross, Bryan Routledge, Scott Shane, Ralph Winter, and seminar participants at the CEPR European Summer Symposium in Financial Markets and the University of Paris-Dauphine, for helpful comments. Able research assistance was provided by Chris Bidner. Financial support from SSHRC (Chemla) is gratefully acknowledged. All errors are ours.
} 


\section{Introduction}

At its peak in 2000, corporate venturing (CV) represented $\$ 16.2$ billion of investments in the U.S. ${ }^{1}$ At the time, 16 cents out of every dollar invested in new ventures came from corporate venturing firms, who participated in about $25 \%$ of all deals. Corporate venturing investments had risen dramatically with entrepreneurial activity during the internet boom, up from $\$ 1$ billion in 1997 , and evaporated just as quickly afterwards, down to $\$ 1.2$ billion in the first 9 months of 2002 (Taylor, 2003). Despite their importance, the nature of corporate venturing and its pro-cyclical fluctuations with entrepreneurial activity are still largely unexplained. ${ }^{2}$ Is corporate venturing simply a way for firms to capture some of the high returns that they observe in entrepreneurial ventures - a "gravy train" rationale - or is it part of a broader corporate strategy? In this paper we propose two novel and complementary explanations for corporate venturing that are based on competition for talent.

We present a model where a firm and a venture capitalist (VC) compete for the recruitment of a star manager who has an idea and a unique skill to run a new venture. The star may choose the VC's offer, in which case the VC finances her project, and she manages the new venture. ${ }^{3}$ Alternatively, she may choose the firm's offer, in which case her task depends on the firm's organizational structure: if organized as a corporation, the firm will assign the star the task of managing its main line of business; while if organized for corporate venturing it can finance the star's project and let her manage the new venture. The main difference between the new venture and the firm's main business is that the star's marginal product of effort is higher in the new project than in the more routine main business.

When returns to venturing are low, financing the star's project is not lucrative for the firm, and competition from the VC is low for the same reason. The firm prefers to organize as a corporation, recruiting the star to manage its main business. As returns to venturing increase, the relative attrac-

\footnotetext{
${ }^{1}$ We define corporate venturing as the financing and development of new business ventures by large established companies, either inside (intrapreneurship) or outside (corporate venture capital) the corporate structure. In the United States, over 200 corporations were listed in the 2002 Directory of Corporate Venturing as investing as active corporate venture capitalists. Corporations also invest in venture capital through specialized institutions such as venture capital funds. At the end of 2001, corporations were the second largest source of capital to venture capital funds, after endowments and foundations, with total commitments of about $\$ 35$ billion (Goldman and Russell, 2002). Although some of these investments, often organized through partnerships, are sometimes included in the definition of corporate venturing, they are not part of our definition here.

${ }^{2}$ As is well known, entrepreneurial activity went through a similar boom-and-bust cycles over the same time period: venture capital investment went from $\$ 14.6$ billion in 1997 to $\$ 105$ billion in 2000 , down to $\$ 17.3$ billion in the first 9 months of 2002 (Brander and Bettignies, 2006). This pro-cyclicality is not new. In the previous two venture capital "waves," in the late 1960s and early 1970s, and then again in the late 1970s and early 1980s, success in venture capital spurred corporate venturing investments which quickly shrank at the end of the booms, in 1973 and 1987 respectively (Gompers and Lerner, 1998, Gompers, 2002).

${ }^{3}$ For expositional reasons, throughout the paper we refer to the star manager as female, the VC as male, and the firm as neutral.
} 
tiveness of corporate venturing increases as well for two reasons. First, investing in a new venture enables the firm to capture some of the higher returns associated with venturing. This is the "gravy train" effect mentioned above. Second, the VC's willingness to bid for the star also increases with returns to venturing, and the star's equilibrium compensation goes up. The firm responds to higher compensation costs by offering higher-powered incentives, which in turn elicit higher managerial effort. Foresighted firms may thus choose corporate venturing as a way of allocating stars where the marginal product of their effort is highest, i.e. in new ventures. We call this the "incentives" rationale for corporate venturing.

Beyond a certain threshold level of returns to venturing, recruiting the star would become too expensive for the firm, if it were organized as a corporation. Faced with constant benefits but rising compensation costs, it could no longer match offers made by the VC, who would "steal" away the star manager. We show that when returns to venturing are high enough for this problem to arise, corporate venturing emerges as a solution, enabling the firm to hire/retain talented managers who would otherwise take another job. We call this the "recruitment/retention" rationale for corporate venturing.

The key difference between the gravy train and incentives rationales on the one hand, and the recruitment explanation on the other, is that they take place at different levels of returns to venturing. Indeed, at low and moderate levels, the firm anticipates that it can successfully recruit the star regardless of its organizational form, and therefore its organizational choice is more about how to best allocate the star across its activities. When the gravy train and incentives effects become sufficiently large, the optimal allocation of talent switches from the main business (corporation) to a new venture (corporate venturing).

In contrast, at high levels of returns to venturing, the firm anticipates that if it organizes as a corporation, it will not recruit the star. This adds both a cost and a benefit to the relative attractiveness of corporate venturing. On the one hand, by organizing for corporate venturing, the firm has to pay a large compensation cost in order to recruit the star, a cost which would be avoided if it organized as a corporation and did not recruit. In our stylized model this cost exactly offsets the gravy train and incentives effects mentioned above, as competition for talent ensures that the star extracts all expected rents from the new venture. On the other hand, organizing for corporate venturing and allowing the star to develop her idea inside the firm may be a way to prevent her from developing it somewhere else, e.g. with a VC. 
Suppose that the new venture is correlated to the firm's main business, e.g. through spillovers, which could be positive or negative. These spillovers will likely benefit the main line of business less, or hurt it more, if the venture is developed by the $\mathrm{VC}$ than if it is developed under the umbrella of corporate venturing, because unlike the firm, the $\mathrm{VC}$ will not internalize the impact of the new venture on the firm's main line of business. Hence, at high levels of returns to venturing, although the gravy train and incentives effects disappear, a benefit from recruitment and retention of star employees emerges as the firm attempts to internalize new venture spillovers on its main business.

Despite growing interest, only a few papers have explicitly addressed the question of corporate venturing theoretically. ${ }^{4}$ Anton and Yao (1994, 1995), as well as Anand, Galetovic and Stein (2004), examine this theme in the context of weak property rights. Hellmann (2002) argues that an entrepreneur should seek corporate venturing funding when the venture project is complementary to the parent corporation's main line of business. Amador and Landier (2003) investigate whether innovation is to be implemented inside incumbent firms or outside by venture capitalists, in a model of entrepreneurial optimism. Gromb and Scharfstein (2003) analyze how the tradeoff between information and incentives affects firms' choice between intrapreneurship and direct venture capital financing. ${ }^{5}$ Hellmann (2006) explores a firm's decision to encourage or discourage exploration of new ideas by employees, and shows that it depends chiefly on the allocation of intellectual property rights and the relative value of innovation inside and outside the firm.

The thrust of our contribution to this literature is to place competition for talent at the forefront of the analysis. ${ }^{6}$ This enables us to highlight several new insights and empirical implications. First, we provide the two new explanations for corporate venturing and its pro-cyclical fluctuations that we mentioned: one based on managerial incentives and the optimal allocation of talent; the other based

\footnotetext{
${ }^{4}$ For an excellent review of this literature, and of employee innovation in general, see Hellmann (2006).

${ }^{5}$ Gromb and Scharfstein (2003) consider the "safety net" that intrapreneurship provides to entrepreneurs, who can get their corporate job back in case of failure. Intrapreneurship provides lower incentives than VC financing because of the safety net, but it comes with an informational advantage about the quality of the failed intrapreneur. In their paper, as well as in Landier's (2006), the market perception of the reasons for failure plays a central role in reaching the equilibrium level of entrepreneurship. Dix and Gandelman (2003) also look at a similar choice between intrapreneurship and corporate venture capital, but the tradeoff is based on somewhat different informational asymmetries.

${ }^{6}$ Amador and Landier (2003) and Anand et al. (2004) also developed models in which a manager/entrepreneur with an innovative idea chooses between contracts offered by an incumbent firm and a VC. A key feature of Amador and Landier's model is that the entrepreneur is subject to an optimism bias about her idea. The VC's advantage in recruiting her lies in its superior ability to exploit her bias through contracts, while the incumbent firm has a cost advantage due to potential synergies with existing assets. Interestingly, the authors find that the relative recruiting advantage of the $\mathrm{VC}$ increases with project value - a variable similar to the "returns to venturing" measure used in our model - and predict that high value projects will be financed outside the firm. In contrast our model suggests that high value projects may still be developed inside the firm, as it attempts to internalize the spillovers on its main line of business. In Anand et al., the focus is on studying how the strengths of property rights, and the centralization of operations, affect a firm's ability to recruit a talented manager. They do not analyze the effects of changes in returns to venturing and competition for talent.
} 
on recruiting and retaining star managers as a spillover internalization strategy. Second, we highlight the importance of competition for talent as a determinant of firms' organizational strategy. We show that - by generating the incentives and recruiting effects - competition has an unambiguously positive impact on corporate venturing, inducing firms to switch to corporate venturing "sooner" as returns to venturing increase. Third, we suggest that spillovers from the new venture to the firm's main business may have a positive impact on corporate venturing. Interestingly, in contrast with Helmann (2002), corporate venturing may still be optimal even when spillovers are large and negative, as the firm attempts to preempt the VC's development of the new venture, which would lead to a negative spillover effect of an even greater magnitude. Fourth, we extend the model to adress issues related to "contractual incompleteness." This enables us to examine the impact of intellectual property (IP) rights on the prevalence of corporate venturing, as well as the effects of returns to venturing on the optimal allocation of control rights between the star and the corporate parent. We suggest that weaker IP protection may be favorable to corporate venturing, and that increased venturing returns may induce corporate venturing firms to allocate more control rights to the star, thereby switching from tighter controlled structures, such as internal ventures, to more autonomous structures, such as corporate venture capital. Finally, we underline the link between competition for talent, economic efficiency, and corporate venturing: we point out that there may be less corporate venturing in equilibrium than is socially desirable, but that competition - by increasing the prevalence of corporate venturing - may improve economic efficiency.

The paper is organized as follows. Section 2 describes the model. Section 3 analyzes competition for star managers when the firm is organized as a corporation, while section 4 looks at these issues in the context of corporate venturing. In section 5 , we characterize the optimal organizational choice and how it is affected by returns to venturing, competition for talent, and spillover effects. Section 6 extends the model to contractual incompleteness and examines the optimal structure of corporate venturing; while section 7 discusses other extensions to the model. Section 8 presents the key empirical implications of the model, and relates them to the empirical literature. Section 9 concludes. The characterization of the main optimization program is in the appendix at the end of the paper; all proofs are in the online supplement. 


\section{The Model}

\subsection{Basic Setup}

A firm intends to recruit a star manager/entrepreneur, and anticipates competition from other institutions in the "market for talent." 7 This star manager has an idea for a new venture that requires financing. The firm must choose between two organizational structures $F \in\{C, C V\}$, which differ primarily in the way they allocate talent.

If organized as a corporation $(C)$, the firm focuses on its core competency, and devotes all its attention and resources to its existing line of business. If recruited, the star would manage the main business, and her idea for a new venture is not pursued.

If involved in corporate venturing $(C V)$, the firm does not focus exclusively on its main business, and is organized so as to be able to pursue new opportunities. This organizational change could take various forms, from setting up a committee in charge of evaluating employees' new venture ideas, to the funding of a full-fledged fund devoted to new venture investments, similar to standard venture capital funds. Under this organizational form, conditional on recruiting the manager, the firm finances her idea, and the star manages the new venture.

For simplicity, we assume that the main business yields a (dollar) return $M$ with certainty if managed by the star, and $M^{-}<M$, otherwise. The new venture can only be valuable if it is run by the star manager, and it can turn out to be of two types. It may be a "base hit," in which case it yields a base dollar return $\Pi \geq \Pi_{\min }$ (net of initial capital outlay), or a "home run," in which case the return is $\Pi+\pi$, with $\pi>0$. The star exerts a non-verifiable effort $e$ which strictly increases the probability of a home run. For simplicity we assume this probability to be $e$. Hence, the new venture yields an expected return $\Pi+e \pi$ (gross of effort cost) when managed by the star, and zero otherwise. The star is assumed to be risk-neutral and wealth-constrained; and her cost of effort is $c(e)=\frac{k}{2} e^{2}$.

A key difference between the main line of business and the new venture is that the star's marginal product of effort is larger in the latter than in the former. The basic idea is that while new ventures are highly risky and the star can have a large impact on the probability of success, the main line of business may include (relatively) more of a routine job where the star's effort has a lower impact. One could also argue that the management of the new venture likely involves a product that is closer to

\footnotetext{
${ }^{7}$ In this paper, we view managerial talent and entrepreneurial talent as requiring similar skills, which appears to be consistent with the fact that firms lose a large number of successful managers during times of high entrepreneurship (see footnote 25 in section 8 . This contrasts with, for instance, Lazear (2003), who argues that entrepreneurial talent requires a broad of skills while managerial talent requires perhaps more outstanding, but also more specialized skills.
} 
the beginning of the life-cycle than its main business counterpart, and that managerial effort has a larger impact at the beginning of a product's life-cycle than at its end.

The main business and the new venture are linked in that the new venture yields a spillover, $S \in \mathbb{R}$, on the main business. The spillover could be positive and represent superior access to a new technology for the main line of business, for example, or may capture a reduced-form complementarity between the products developed in the new venture and those developed in the main business. Alternatively, $S$ may be negative and capture some form of cannibalization of the main venture products by the new venture products. The spillovers enable us to take into account the idea, highlighted by Hellmann (2002), that the venturing firms' objective is not restricted to maximizing the value of the stand-alone ventures. Here, the broader objective is the value created by the project as a stand-alone project plus the spillovers to the main line of business. In our setting, conditional on hiring the star, the firm's gross (i.e. excluding the compensation cost) expected return is $M$ when organized as a corporation, and $\Pi+e \pi+M^{-}+S$ when organized for corporate venturing.

The firm may fail to recruit the star, who may turn to another institution, say a venture capitalist (VC), to finance her new venture idea. ${ }^{8}$ If the star chooses to develop the new venture with the $\mathrm{VC}$, the firm, regardless of its organizational form $(C$ or $C V)$, has no access to the star's talent, but may still receive a spillover $(S-\delta)$ from the new venture to its main business. In other words, the spillover from the new venture to the firm's main business is lower, be it positive or negative, if the new venture is developed by the venture capitalist than if it is developed under corporate venturing, and $\delta \geq 0$ represents this spillover differential. This is simply a reduced-form way of capturing the idea that, unlike the firm, the VC does not internalize the impact of spillovers on the firm's main line of business.

Thus, if the star chooses to go with the VC, the firm's expected payoff is $M^{-}+S-\delta$ regardless of its organizational form. The $\mathrm{VC}$ expects a gross payoff $\Pi+e \pi$ from the project if he can recruit the star and finance the venture; and zero otherwise.

Finally, the following two regularity conditions on the parameters will simplify our analysis (our results still obtain without these conditions, unless otherwise specified):

$$
\begin{aligned}
M-\left(M^{-}+S\right) & >\frac{\pi^{2}}{8 k}+\varepsilon, \text { with } \varepsilon \rightarrow 0, \\
\Pi_{\min } & =-\frac{\pi^{2}}{4 k}+\varepsilon, \text { with } \varepsilon \rightarrow 0 .
\end{aligned}
$$

\footnotetext{
${ }^{8}$ There may be more than one competitor (VC), but there is no loss of generality in focusing on the most productive one (in the use of the star's talent/idea).
} 


\subsection{Competition for Talent and Incentive Contracts}

Competition affects the offers made by the firm and the VC to the star manager. If the firm is organized as a corporation and focuses on its main business, the value of recruiting the star does not depend on her non-contractible effort. Hence, the corporation's contractual offer is a constant wage $W_{C}$, and the star receives a net payoff $U_{C}=W_{C}$.

In contrast, if the firm engages in corporate venturing, its expected payoff depends on the effort level $e$ exerted by the star manager, who must thus be incentivized. Since effort cannot be contracted upon, the star's compensation package is made contingent on the new venture's realized payoff. Specifically, the star manager receives a fixed wage $\alpha_{C V}$ with certainty and a fraction $\beta_{C V}$ of incremental payoff $\pi$ in case of a home run. The fraction $\beta_{C V}$ can be interpreted as a fraction of call options allocated to the star manager, and will affect her effort choice, $e_{C V}=e\left(\beta_{C V}\right){ }^{9}$ The star's expected compensation can thus be expressed as $W_{C V}=\alpha_{C V}+e_{C V} \beta_{C V} \pi$, and her net expected payoff is $U_{C V}=W_{C V}-c\left(e_{C V}\right)$. Similarly, the competing VC also offers a fixed wage, $\alpha_{V C}$, and a fraction of call options, $\beta_{V C}$, to the star, which imply an expected compensation $W_{V C}=\alpha_{V C}+e_{V C} \beta_{V C} \pi$, and a net payoff $U_{V C}=W_{V C}-c\left(e_{V C}\right)$.

\subsection{Timing of the Game}

The timing is as follows.

- At date 0 , Nature reveals parameters $\Pi, \pi, M, M^{-}, S, k$ and $\delta$, and the firm chooses its organizational form $F \in\{C, C V\}$.

- At date 1, the firm and the VC both make a contractual offer to the star manager. Specifically, if $F=C$, the firm offers $W_{C}$ to the star. If $F=C V$, the firm offers $\left\{\alpha_{C V}, \beta_{C V}\right\}$, which implies a net expected payoff $U_{C V}$ to the star. The competitor offers $\left\{\alpha_{V C}, \beta_{V C}\right\}$, which yields $U_{V C}$ to the star.

- At date 2, the star chooses one of the two offers.

- At date 3, the star exerts effort.

- At date 4, the returns are generated and the payoffs are distributed.

\footnotetext{
${ }^{9}$ As documented in Chemla, Habib, and Ljungqvist (2005) and Schmidt (2003), such clauses appear to be frequently used in venture capital (and in particular corporate venture capital) contracts. Our results hold if the compensation package can also be made contingent on the spillover or on the payoff to the main line of business. Such contracts are not common practice.
} 


\section{The Corporation}

In this section and the next, we analyze competition for the star manager at date 1, taking the firm's organizational choice as given. We start by analyzing the case of the corporation, and then move on to corporate venturing in section 4 .

\subsection{Contract Offered by the Corporation, Taking $U_{V C}$ as Given}

The firm determines the optimal contract and its resulting expected payoff if it recruits the star, and if it does not, and then chooses among these two strategies the one that maximizes its payoff.

If it intends to recruit the star manager, the firm maximizes the following program:

$$
\max _{W} M-W
$$

subject to the star's individual rationality (IR) constraint:

$$
W \geq U_{V C},
$$

where $U_{V C}$ represents the star manager's (net) reservation payoff (henceforth RP), i.e. her net expected payoff if she chooses the VC's offer to finance the new venture. We assume that if indifferent, the star will choose the firm's offer, hence the weak inequality in (4). The solution is simple: The corporation offers $W_{C}^{r}\left(U_{V C}\right)=U_{V C}$ to the star, recruiting her at minimum cost, and generating a net payoff $P_{C}^{r}\left(U_{V C}\right)=M-W_{C}^{r}\left(U_{V C}\right)=M-U_{V C} \cdot{ }^{10}$ In contrast, if it does not intend to recruit the star, the firm offers any $W_{C}^{n r}\left(U_{V C}\right)<U_{V C}$, and obtains total expected payoff $P_{C}^{n r}=M^{-}+S-\delta$.

We define $\bar{U}_{V C}$ as the threshold RP to the star (from the $\mathrm{VC}$ ) such that the corporation is indifferent between recruiting her or not: $\bar{U}_{V C}=M-M^{-}-(S-\delta)$. Regularity condition (1) implies $\bar{U}_{V C}>\frac{\pi^{2}}{8 k}$.

Since $P_{C}^{r}\left(U_{V C}\right)$ is strictly decreasing in $U_{V C}$ the corporation's best response is to recruit the star with an offer $W_{C}^{r}\left(U_{V C}\right)$ if $U_{V C} \leq \bar{U}_{V C}$, and to not recruit her and offer any $W_{C}^{n r}\left(U_{V C}\right) \leq W_{C}^{r}\left(U_{V C}\right)$ if $U_{V C}>\bar{U}_{V C}$.

\footnotetext{
${ }^{10}$ Throughout the paper, superscript $r$ (resp. $n r$ ) stands for "recruiting" (resp. "not recruiting").
} 


\subsection{Contract Offered by the Competing VC, Taking $U_{C}$ as Given}

The same type of (backward induction) process can be used to determine the VC's best response correspondence. The characterization of the optimal contract is detailed in the appendix at the end of the paper. If it intends to recruit the star manager, the VC maximizes the following program:

$$
\max _{\alpha, \beta} \Pi+e \pi-(\alpha+e \beta \pi)
$$

subject to the star's incentive compatibility (IC) constraint (6), individual rationality (IR) constraint (7) and limited liability constraint (8):

$$
\begin{aligned}
e & \in \underset{e}{\arg \max } \alpha+e \beta \pi-\frac{k}{2} e^{2}, \\
U_{C} & <\alpha+e \beta \pi-\frac{k}{2} e^{2}, \\
\alpha & \geq 0, \beta \geq 0,
\end{aligned}
$$

where $U_{C}$ is the star's RP (offered by the corporation). The optimal contract can be described as follows:

$$
\left\{e_{V C}^{r}, \alpha_{V C}^{r}, \beta_{V C}^{r}\right\}\left(U_{C}\right)=\left\{\begin{array}{ll}
\left\{\frac{\pi}{2 k}, 0, \frac{1}{2}\right\} & \forall U_{C} \in\left[0, \frac{\pi^{2}}{8 k}\right) \\
\left\{\sqrt{\frac{2}{k} U_{C}}, \varepsilon, \frac{\sqrt{2 k U_{C}}}{\pi}\right\} & \forall U_{C} \in\left[\frac{\pi^{2}}{8 k}, \frac{\pi^{2}}{2 k}\right) \\
\left\{\frac{\pi}{k}, U_{C}+\varepsilon-\frac{\pi^{2}}{2 k}, 1\right\} & \forall U_{C} \in\left[\frac{\pi^{2}}{2 k}, \infty\right)
\end{array}\right\} .
$$

It is easy to check that in the first-best (FB) environment with a contractible effort, one would obtain $e^{F B}=\frac{\pi}{k}$. As is well-known, in our setting with non-verifiable effort and limited liability for the star, the (second-best) effort level is weakly lower than the first-best level: $e_{V C}^{r}\left(U_{C}\right) \leq e^{F B} \cdot{ }^{11}$ More interestingly for our purpose below, the following result emerges from this characterization:

Lemma 1 The power of incentives $\beta_{V C}^{r}$ offered by the VC, and the star's effort $e_{V C}^{r}$, are both weakly increasing in the star's reservation payoff $U_{C}$.

When $U_{C}$ is low $\left(U_{C} \in\left[0, \frac{\pi^{2}}{8 k}\right)\right)$ the contract offered by the VC to hire the star would leave rents to the star in order to elicit the desired effort level. An increase in $U_{C}$ would simply reduce the rent, but

\footnotetext{
${ }^{11}$ The star's equilibrium effort depends on her marginal benefit from effort, which is her expected share of incremental profits in the good state, $\beta \pi$ (see IC constraint (6)). The unconstrained program would generate first-best effort by giving the star full residual control over incremental profits, i.e. $\beta=1$, with the VC extracting all expected rents through a fixed payment $\alpha<0$. However, this payment would violate the star's LL constraint $\alpha \geq 0$. Hence any share of profits $\beta \pi$ given to the star is forfeited for good. This implies $\beta \leq 1$, and $e_{V C}^{r}\left(U_{C}\right) \leq e^{F B}$.
} 
would have no impact on the contract $\left\{0, \frac{1}{2}\right\}$ offered, nor on the resulting effort $e_{V C}^{r}=\frac{\pi}{2 k}$. However, when $U_{C}$ belongs to $\left[\frac{\pi^{2}}{8 k}, \frac{\pi^{2}}{2 k}\right)$, IR constraint (7) is binding: The VC can no longer offer $\left\{0, \frac{1}{2}\right\}$, because the star would turn down the offer and take the superior rival offer $U_{C}$. Instead, the VC offers a contract such that the star's net expected payoff is higher than $U_{C}$ by a small amount $\varepsilon$. As $U_{C}$ rises, the VC must increase his bid, which he does by increasing $\beta_{V C}^{r}$, thus "killing two birds with one stone." First, he increases the star's expected compensation and ensures her participation. Second, he increases the star's marginal benefit from effort, $\beta \pi$, and these higher-powered incentives lead to a higher effort level. This is the key intuition behind Lemma 1. Finally, as $U_{C}$ becomes "high" and enters $\left[\frac{\pi^{2}}{2 k}, \infty\right)$, offering the same contract as in $\left[\frac{\pi^{2}}{8 k}, \frac{\pi^{2}}{2 k}\right)$ would lead to an excessively high effort. Instead, the VC offers a contract that elicits the first-best effort and ensures participation.

Using (9), one can easily derive the expected net payoff for the star, $U_{V C}^{r}\left(U_{C}\right)=W_{V C}^{r}\left(U_{C}\right)-$ $c\left(e_{V C}^{r}\left(U_{C}\right)\right)$, and for the $\mathrm{VC}, P_{V C}^{r}\left(U_{C}\right)=\Pi+e_{V C}^{r}\left(U_{C}\right) \pi-W_{V C}^{r}\left(U_{C}\right)$, if the star is hired by the VC:

$$
\left\{U_{V C}^{r} ; P_{V C}^{r}\right\}\left(U_{C}\right)=\left\{\begin{array}{ll}
\left\{\frac{\pi^{2}}{8 k}, \Pi+\frac{\pi^{2}}{4 k}\right\} & \forall U_{C} \in\left[0, \frac{\pi^{2}}{8 k}\right) \\
\left\{U_{C}+\varepsilon, \Pi+\sqrt{\frac{2 U_{C}}{k}} \pi-2 U_{C}-\varepsilon\right\} & \forall U_{C} \in\left[\frac{\pi^{2}}{8 k}, \frac{\pi^{2}}{2 k}\right) \\
\left\{U_{C}+\varepsilon, \Pi+\frac{\pi^{2}}{2 k}-U_{C}-\varepsilon\right\} & \forall U_{C} \in\left[\frac{\pi^{2}}{2 k}, \infty\right)
\end{array}\right\}
$$

The VC will recruit the star provided his recruitment payoff $P_{V C}^{r}>P_{V C}^{n r}=0$. We show that for each value of $\Pi \geq \Pi_{\min }$ there exists a unique threshold reservation payoff $\bar{U}_{C} \geq \frac{\pi^{2}}{8 k}$ defined implicitly as the solution to:

$$
P_{V C}^{r}\left(\bar{U}_{C}\right)=\Pi+e_{V C}^{r}\left(\bar{U}_{C}\right) \pi-W_{V C}^{r}\left(\bar{U}_{C}\right)=0
$$

such that, if $U_{C}<\bar{U}_{C}$ the VC recruits the star with a contract $\left\{\alpha_{V C}^{r}\left(U_{C}\right), \beta_{V C}^{r}\left(U_{C}\right)\right\}$ to the star; and if $U_{C} \geq \bar{U}_{C}$, the $\mathrm{VC}$ does not recruit the star (and offers any contract $\left\{\alpha_{V C}^{n r}, \beta_{V C}^{n r}\right\}$ such that $\left.U_{V C}\left(\alpha_{V C}^{n r}, \beta_{V C}^{n r}\right) \leq U_{C}\right)$

\subsection{Nash Equilibria of the Subgame}

In the foregoing two subsections, we characterized the corporation's best-response for any $U_{V C} \geq 0$, and the VC's best response for any given $U_{C} \geq 0$. The determination of Nash equilibria (NE) follows directly by intersecting these two correspondences. 
Proposition 1 The Nash Equilibria in this subgame are characterized as follows:

Case 1: $\bar{U}_{C} \leq \bar{U}_{V C}$ : The corporation offers $W_{C 1}^{*}\left(\bar{U}_{C}\right)=W_{C}^{r}\left(\bar{U}_{C}\right)=\bar{U}_{C}$, which is also the payoff to the star. The VC offers one of many possible contracts $\left\{\alpha_{V C 1}^{*}, \beta_{V C 1}^{*}\right\}$ such that $U_{V C 1}^{*}\left(\alpha_{V C 1}^{*}, \beta_{V C 1}^{*}\right)=$ $\bar{U}_{C}$. The star takes the corporation's offer, and this leads to payoffs $P_{C 1}^{*}\left(\bar{U}_{C}\right)=M-W_{C 1}^{*}\left(\bar{U}_{C}\right)$ to the corporation and $P_{V C 1}^{*}=0$ to the $V C$.

Case 2: $\bar{U}_{C}>\bar{U}_{V C}$ : There exists a unique $N E$ where the corporation offers $W_{C 2}^{*}=\bar{U}_{V C}$ and the VC offers $\left\{\alpha_{V C 2}, \beta_{V C 2}^{*}\right\}\left(\bar{U}_{V C}\right)=\left\{\alpha_{V C}^{r}, \beta_{V C}^{r}\right\}\left(\bar{U}_{V C}\right)$. The VC's offer yields a payoff $U_{V C 2}^{*}\left(\bar{U}_{V C}\right)=$ $\bar{U}_{V C}+\varepsilon$ with $\varepsilon \rightarrow 0$; and the star opts for the VC's offer. The VC and the corporation receive $P_{V C 2}^{*}\left(\bar{U}_{V C}\right)=P_{V C}^{r}\left(\bar{U}_{V C}\right)=\Pi+e_{V C}^{r}\left(\bar{U}_{V C}\right) \pi-W_{V C}^{r}\left(\bar{U}_{V C}\right)$ and $P_{C 2}^{*}=M^{-}+S-\delta$, respectively.

Consider the case where $\bar{U}_{C} \leq \bar{U}_{V C}$. Clearly, the star cannot receive less than $\bar{U}_{C}$, otherwise at least one of the rivals would make a higher offer to attract the star. By definition of $\bar{U}_{C}$, the VC will not outbid an offer from the corporation that equals (or is higher than) $\bar{U}_{C}$. Hence, the corporation recruits the star at the lowest possible cost, i.e. $\bar{U}_{C}$. Note that there exist many NE, all with $W_{C 1}^{*}\left(\bar{U}_{C}\right)=\bar{U}_{C}$, but each with a different combination of $\left\{\alpha_{V C 1}^{*}, \beta_{V C 1}^{*}\right\}$. Importantly, all of these NE yield the same outcome, and the same payoffs to the different players. In the case where $\bar{U}_{C}>\bar{U}_{V C}$, the intuition is similar, with the VC offering $\bar{U}_{V C}+\varepsilon$ and hiring the star at minimum cost.

The base return to venturing $\Pi$ is one factor that will affect the relative threshold RPs and hence whether the star is hired by the corporation or by the VC, and in turn the corporation net expected payoff. ${ }^{12}$ When $\Pi$ increases, the VC's net expected payoff after hiring the star also increases. Hence threshold RP $\bar{U}_{C}$ goes up as well. In contrast, the corporation, which focuses on its main line of business, remains unaffected by an increase in $\Pi$, so its threshold $\mathrm{RP}, \bar{U}_{V C}$, does not vary with $\Pi$.

Lemma 2 If the firm is organized as a corporation, there exists a threshold level of return to venturing $\widehat{\Pi} \geq \Pi_{\min }-$ defined as the level of $\Pi$ such that $\bar{U}_{C}(\widehat{\Pi})=\bar{U}_{V C}-$ such that the firm recruits the star when $\Pi \in A_{1}=\left[\Pi_{\min }, \widehat{\Pi}\right]$ and the $V C$ recruits the star when $\Pi \in A_{2}=(\widehat{\Pi}, \infty)$. The expected net payoff to the corporation can be written:

$$
P_{C}^{*}(\Pi)=\left\{\begin{array}{ll}
P_{C 1}^{*}(\Pi)=M-W_{C 1}^{*}\left(\bar{U}_{C}(\Pi)\right)=M-\bar{U}_{C}(\Pi) & \text { for } \Pi \in A_{1} \\
P_{C 2}^{*}=M^{-}+S-\delta & \text { for } \Pi \in A_{2}
\end{array}\right\}
$$

\footnotetext{
${ }^{12}$ Our results would be qualitatively the same if $\pi$ rather than $\Pi$ was allowed to vary.
} 
When the return to venturing $\Pi$ is small and close to $\Pi_{\min }$, the $\mathrm{VC}$ has little to gain from recruiting, and the maximum amount it can "bid" for the star, $\bar{U}_{C}(\Pi)$, is low. The corporation can therefore recruit the star by offering a salary $W_{C 1}^{*}\left(\bar{U}_{C}(\Pi)\right)$, which grants the star the same payoff as the VC's best bid. As the return to venturing increases, so does the VC's bid for the star, since $\bar{U}_{C}^{\prime}(\Pi)>0$. The corporation must increase its offer to the star accordingly, and this negative "compensation cost" effect (of an increase in $\Pi$ ) decreases its net payoff. As the return to venturing becomes large and crosses the

threshold $\widehat{\Pi}$, it becomes too expensive for the corporation to match the VC's offer. Therefore, beyond $\widehat{\Pi}$ the corporation does not match the VC's offer, and the VC recruits the star.

Proposition 2 An increase in retuns to venturing $\Pi$ increases the VC's valuation for the star. This prompts the corporation to make a higher bid for the star, thereby reducing its net expected payoff. Due to this "compensation cost" effect, the relative attractiveness of recruiting the star decreases with $\Pi$, and it is negative when $\Pi>\widehat{\Pi}$.

\section{Corporate Venturing}

\subsection{Contract Offered by the Corporate Venturing Firm, Taking $U_{V C}$ as Given}

The corporate venturing (CV) firm's program is nearly identical to the VC's program examined in Subsection 3.2. If it intends to recruit the star manager, the objective function is the same, up to constant $\left(M^{-}+S\right)$ :

$$
\max _{e, \alpha, \beta} \Pi+e \pi-(\alpha+e \beta \pi)+M^{-}+S
$$

the IC and LL constraints are the same as in (6) and (8), respectively; and the IR constraint,

$$
\alpha+e \beta \pi-\frac{k}{2} e^{2} \geq U_{V C s}
$$

differs from (7) only in that the star's RP is the VC's offer $U_{V C s}$ rather than $U_{C}$, and in that the inequality is weak. ${ }^{13}$

Hence, the equilibrium $e_{C V}^{r}, \alpha_{C V}^{r}, \beta_{C V}^{r}$, and $W_{C V}^{r}=\alpha_{C V}^{r}+e_{C V}^{r} \beta_{C V}^{r} \pi$ are as described in (9), but with $\varepsilon=0$ and $U_{V C s}$ instead of $U_{C}$. As in Subsection 3.2, for any $\Pi \geq \Pi_{\min }$ there exists a unique

\footnotetext{
${ }^{13}$ The weak inequality reflects the assumption that if indifferent the star will choose the firm's offer. The subscript $V C s$ refers to the $\mathrm{VC}$ in this second subgame rather than in the previous (first) subgame.
} 
threshold RP to the star $\bar{U}_{V C s}$ such that if $U_{V C s} \leq \bar{U}_{V C s}$ the CV firm recruits the star with an offer $\left\{\alpha_{C V}^{r}\left(U_{V C s}\right), \beta_{C V}^{r}\left(U_{V C s}\right)\right\}$; and if $U_{V C s}>\bar{U}_{V C s}$ the CV firm offers any contract $\left\{\alpha_{C V}^{n r}, \beta_{C V}^{n r}\right\}$ such that $U_{C V}\left(\alpha_{C V}^{n r}, \beta_{C V}^{n r}\right)<U_{V C s}$ and does not hire the star. Here, $\bar{U}_{V C 2}$ is defined implicitly as the solution to $P_{C V}^{r}\left(\bar{U}_{V C s}\right)=P_{C V}^{n r}$, that is:

$$
\left[\Pi+e_{C V}^{r}\left(\bar{U}_{V C s}\right) \pi-W_{C V}^{r}\left(\bar{U}_{V C s}\right)\right]+\left[M^{-}+S\right]=M^{-}+S-\delta
$$

where the first square-bracketed term represents the CV firm's expected payoff from the new venture, the second square-bracketed term represents its payoff from the main business, and the right-hand side represents its payoff if it does not recruit.

\subsection{Contract Offered by the Competing VC, Taking $U_{C V}$ as Given}

The program is the same as in Subsection 3.2, and hence so is the contractual offer, simply replacing $U_{C}$ by $U_{C V}, \bar{U}_{C}$ by $\bar{U}_{C V}$, and subscript $V C$ by $V C s$. For each value of $\Pi \geq \Pi_{\min }$ there exists a unique threshold $\bar{U}_{C V}=\bar{U}_{C}$, defined in (11), such that if $U_{C V}<\bar{U}_{C V}$ the VC recruits the star with a contract offer $\left\{\alpha_{V C 2}^{r}\left(U_{C V}\right), \beta_{V C 2}^{r}\left(U_{C V}\right)\right\}$; and if $U_{C V} \geq \bar{U}_{C V}$, the VC does not recruit the star, and it offers any contract $\left\{\alpha_{V C s}^{n r}, \beta_{V C s}^{n r}\right\}$ such that $U_{V C s}\left(\alpha_{V C s}^{n r}, \beta_{V C s}^{n r}\right) \leq U_{C V}$.

\subsection{Nash Equilibria of the Subgame}

As noted above, the CV firm's program and the VC's program generate the same equilibrium effort functions $\left(e_{C V}^{r}()=.e_{V C s}^{r}().\right)$, and very similar managerial compensation functions $\left(W_{C V}^{r}(.) \approx\right.$ $\left.W_{V C s}^{r}().\right)$. Comparing (11) and (15), since $\delta \geq 0$, the surplus generated by the star for the CV firm is always higher than for the VC.

If the VC recruits the star, the effects of spillovers on the firm's main line of business will not be internalized, and hence the spillovers will be smaller - by an amount $\delta$ - than if the $C V$ firm recruits the star and internalizes the impact of spillovers. This benefit $\delta$ from recruiting does not accrue to the VC, who has only one project and is not affected by spillovers. ${ }^{14}$ As a result, the CV firm's threshold $\mathrm{RP}$ is higher than the VCs, and the $\mathrm{CV}$ firm successfully recruits the star. The highest bid the VC can offer the star is $\bar{U}_{C V}$; but since $\bar{U}_{V C s} \geq \bar{U}_{C V}$, the CV firm matches that bid and hires the star. Formally, the equilibria can be characterized as follows:

\footnotetext{
${ }^{14}$ Spillovers to the VC's other projects or lines of business are examined in Subsection 7.2.
} 
Proposition 3 In equilibrium the $C V$ firm recruits the star by offering contract $\left\{\alpha_{C V}^{*}, \beta_{C V}^{*}\right\}\left(\bar{U}_{C V}\right)=$ $\left\{\alpha_{C V}^{r}, \beta_{C V}^{r}\right\}\left(\bar{U}_{C V}\right)$. This generates a payoff $U_{C V}^{*}\left(\bar{U}_{C V}\right)=\bar{U}_{C V}$ to the star, a compensation cost $W_{C V}^{*}\left(\bar{U}_{C V}\right)=W_{C V}^{r}\left(\bar{U}_{C V}\right)$ to the firm, and an equilibrium effort $e_{C V}^{*}\left(\bar{U}_{C V}\right)=e_{C V}^{r}\left(\bar{U}_{C V}\right)$. The VC offers one of many possible contracts $\left\{\alpha_{V C s}^{*}, \beta_{V C s}^{*}\right\}$ such that $U_{V C s}^{*}\left(\alpha_{V C s}^{*}, \beta_{V C s}^{*}\right)=\bar{U}_{C V}$. The net expected payoffs to the $C V$ firm and to the VC are $P_{C V}^{*}\left(\bar{U}_{C V}\right)=\Pi+e_{C V}^{*}\left(\bar{U}_{C V}\right) \pi-W_{C V}^{*}\left(\bar{U}_{C V}\right)+$ $M^{-}+S$ and $P_{V C s}^{*}=0$, respectively. ${ }^{15}$

In this subgame, returns to venturing $\Pi$ have no impact on recruitment. The $C V$ firm recruits the star for all $\Pi \geq \Pi_{\min }$ because an increase in $\Pi$ affects the threshold RP levels for both the CV firm and the VC, $\bar{U}_{V C s}$ and $\bar{U}_{C V}$, similarly, such that $\bar{U}_{V C 2}$ remains higher than $\bar{U}_{C V}$ for all $\Pi$.

Returns to venturing do affect the expected net payoff from corporate venturing in several ways, however. Note that the $C V$ firm's compensation cost can be expressed as the sum of the star's net payoff and her cost of effort, $W_{C V}^{*}\left(\bar{U}_{C V}\right)=\bar{U}_{C V}+c\left(e_{C V}^{*}\left(\bar{U}_{C V}\right)\right)$; and recall from the previous subgame that $\bar{U}_{C V}(\Pi)=\bar{U}_{C}(\Pi)$ is a strictly increasing function of $\Pi$ for all $\Pi \geq \Pi_{\min } \cdot{ }^{16}$ We can write the CV firm's payoff as:

$$
P_{C V}^{*}(\Pi)=\Pi-\bar{U}_{C V}(\Pi)+\left[e_{C V}^{*}\left(\bar{U}_{C V}(\Pi)\right) \pi-c\left(e_{C V}^{*}\left(\bar{U}_{C V}(\Pi)\right)\right)\right]+\left[M^{-}+S\right],
$$

where $\Pi$ is the base return to venturing, $\bar{U}_{C V}(\Pi)$ is the net payoff captured by the star, the first square-bracketed term represents the marginal expected return from a "home run", and the second one represent rents from the the main line of business.

Intuitively, an increase in $\Pi$ has:

- A positive "gravy train" effect that takes place through $\Pi$, and that increases the payoff to firms involved in new ventures, including the CV firm.

- A negative "compensation cost" effect that takes place through $\bar{U}_{C V}(\Pi)=\bar{U}_{C}(\Pi)$, and that is identical to the one faced by the corporation. An increase in $\Pi$ increases the VC's ability to "bid" for star managers; and this prompts the corporation to increase its own bid for the star, thereby reducing its net expected payoff.

\footnotetext{
${ }^{15}$ As in the previous subgame, there exist many NE, all with contractual offer $\left\{\alpha_{C V}^{*}, \beta_{C V}^{*}\right\}$ by the $\mathrm{CV}$ firm, but each with a different combination of $\left\{\alpha_{V C s}^{*}, \beta_{V C s}^{*}\right\}$. All of these NE yield the same outcome, and the same payoff to the different players.

${ }^{16}$ Clearly, $\bar{U}_{C V}(\Pi)=\bar{U}_{C}(\Pi)$ since these two thresholds make the same VC indifferent between recruiting or not. As discussed in the previous subgame, $\bar{U}_{C}^{\prime}(\Pi)>0$ for all $\Pi \geq \Pi_{\min }$.
} 
- A positive "managerial incentives" effect that takes place through $\left[e_{C V}^{*}\left(\bar{U}_{C V}(\Pi)\right) \pi-c\left(e_{C V}^{*}\left(\bar{U}_{C V}(\Pi)\right)\right)\right]$. As $\Pi$ increases the $C V$ firm must increase the star's compensation, but (as highlighted in Lemma 1) this is achieved by (weakly) increasing the power of incentives $\beta_{C V}^{*}$. This has a positive effect on effort $e_{C V}^{*}\left(\bar{U}_{C V}(\Pi)\right)$ and in turn on the marginal expected "home run" return.

Proposition 4 An increase in returns to venturing $\Pi$ has three effects on the expected net payoff from engaging in corporate venturing: A positive "gravy train" effect, the same negative "compensation cost" effect as in the corporation, and a positive "managerial incentives" effect. In equilibrium the compensation cost effect exactly offsets the direct and managerial incentives effects, and $P_{C V}^{*}$ is a constant function of $\Pi$ :

$$
P_{C V}^{*}=M^{-}+S+\varepsilon, \text { with } \varepsilon \rightarrow 0 .
$$

This result that the compensation effect offsets the two other positive effects comes from competition in compensation packages between the $\mathrm{VC}$ and the $\mathrm{CV}$ firm. Because of the technological symmetry between the CV firm and the VC, neither the CV firm no the VC can make any profit on the new venture. This discourages the $\mathrm{VC}$ from recruiting the star, while still keeps the rents on the main line of business, $M^{-}+S+\varepsilon$.

\section{Organizational Choice}

The last step in the characterization of the subgame-perfect equilibrium is the determination of the firm's organizational choice at date 0 . The firm will organize for corporate venturing rather than as a corporation if and only if the relative "attractiveness" of the former organizational form vis-à-vis the latter, $\Delta P^{*}=P_{C V}^{*}-P_{C}^{*}$, is positive. In the following subsections we characterize the firm's optimal organizational form, and how it is affected by returns to venturing, competition for talent, and spillover effects.

\subsection{Impact of Returns to Venturing}

Region $A_{1}: \Pi \in\left[\Pi_{\min }, \widehat{\Pi}\right]:$ The firm can hire the star regardless of its organizational form

Using (12) and (16), the relative attractiveness of corporate venturing in region $A_{1}, \Delta P_{1}^{*}=P_{C V}^{*}-$ 
$P_{C 1}^{*}$, can be written:

$$
\Delta P_{1}^{*}=\Pi+\left[e_{C V}^{*}\left(\bar{U}_{C V}(\Pi)\right) \pi-c\left(e_{C V}^{*}\left(\bar{U}_{C V}(\Pi)\right)\right)\right]-\left[M-\left(M^{-}+S\right)\right] .
$$

In this region, the relative attractiveness of corporate venturing is the net (of effort cost) expected surplus from the new venture - i.e. the base return to venturing plus the expected marginal benefit from hitting a "home run" - minus the foregone rents on the main business $\left[M-\left(M^{-}+S\right)\right]$.

Intuitively, the impact of returns to venturing on $\Delta P_{1}^{*}$ includes the positive gravy train effect and the positive managerial incentives effect on $P_{C V}^{*}$. Since $P_{C}^{*}$ is not subject to these two effects, they increase the relative attractiveness of corporate venturing. In contrast, the compensation costs $\bar{U}_{C V}(\Pi)$ and $\bar{U}_{C}(\Pi)$ - and hence compensation costs effects of a change in $\Pi$ - affect both payoffs in the same way and hence have no impact on $\Delta P_{1}^{*}$.

Note that there may also be a managerial incentives effect with the corporation if we assumed a strictly positive marginal product of effort in the main line of business. The results of the model still hold as long as the marginal product of effort is higher in the new venture than in the main line of business. The intuition is that as the payoff that must be given to the star increases (due to an increase in $\Pi$ ), the firm's optimal response is to increase the power of incentives. The resulting higher effort increases the attractiveness of the organizational forms that allocate the star to higher marginal product of effort activities, i.e., here, corporate venturing.

Lemma 3 In region $A_{1}$, returns to venturing increase the relative attractiveness of corporate venturing through the gravy train and the managerial incentives effects.

\section{Region $A_{2}: \Pi \in(\widehat{\Pi}, \infty)$ : The firm only hires the star if organized for corporate ven- turing}

The relative attractiveness of corporate venturing in region $A_{2}, \Delta P_{2}^{*}=P_{C V}^{*}-P_{C 2}^{*}$, can be written:

$$
\Delta P_{2}^{*}=\Pi+\left[e_{C V}^{*}\left(\bar{U}_{C V}(\Pi)\right) \pi-c\left(e_{C V}^{*}\left(\bar{U}_{C V}(\Pi)\right)\right)\right]-\bar{U}_{C V}(\Pi)+\delta .
$$

There are two key differences between $\Delta P_{1}^{*}$ and $\Delta P_{2}^{*}$. First, in region $A_{2}$, the payoff to the star under corporate venturing is no longer offset by an identical payoff if she is hired by the corporation, because in the latter case there is no recruitment. Hence $-\bar{U}_{C V}(\Pi)$ appears in $\Delta P_{2}^{*}$ and it has 
a negative impact on the relative attractiveness of corporate venturing. Second, the fact that the corporation does not recruit in region $A_{2}$ affects the rents on the main line of business through spillovers from the new venture. With corporate venturing, the new venture is developed under the umbrella of the firm, which yields spillovers $S$ on its main line of business. With the corporation, it is the VC who recruits the star and develops the new venture, leading to smaller spillovers $S-\delta$. The rents on the main line of business are therefore larger under corporate venturing than with the corporation, by an amount $\delta$, the spillover differential; and this has a positive impact on $\Delta P_{2}^{*}$.

We know from Subsection 4.3 that the rents extracted by the star under corporate venturing exactly offset the expected benefit from the new venture. This has two consequences. First, the expression for the relative attractiveness of corporate venturing simplifies to $\Delta P_{2}^{*}=\delta>0$ : corporate venturing is the optimal organizational form in region $A_{2}$, because it allows the firm to successfully recruit the star and internalize the spillover differential. Second, returns to venturing have no impact on $\Delta P_{2}^{*}$. This is because the compensation cost effect associated with corporate venturing (which cancels out in $\Delta P_{1}^{*}$ but not in $\Delta P_{2}^{*}$ ), exactly offsets the direct effect and the managerial effect (which are present in both $\Delta P_{1}^{*}$ and $\left.\Delta P_{2}^{*}\right)$.

Lemma 4 In region $A_{2}, \Delta P_{2}^{*}=\delta \geq 0$. An increase in returns to venturing has no impact on the relative attractiveness of corporate venturing, and corporate venturing is the optimal organizational form.

Lemma 3 and 4 imply that the relative attractiveness of corporate venturing weakly increases with returns to venturing over $\left(\Pi_{\min }, \infty\right)$. Together with regularity conditions $(1)$ and $(2)$ which ensure $\Delta P^{*}\left(\Pi_{\min }\right)<0$, they yield the following Proposition:

Proposition 5 There exists a threshold level $\widetilde{\Pi} \in\left(\Pi_{\min }, \widehat{\Pi}\right]$ such that organizing as a corporation is optimal for all $\Pi \in\left[\Pi_{\min }, \widetilde{\Pi}\right)$, and organizing for corporate venturing is optimal for all $\Pi \in[\widetilde{\Pi}, \infty)$. When returns to venturing are moderate $(\Pi \in[\widetilde{\Pi}, \widehat{\Pi}])$, the firm chooses corporate venturing to take advantage of the gravy train and incentives benefits. When returns to venturing are high $\left(\Pi \in A_{2}=\right.$ $(\widehat{\Pi}, \infty))$, the firm chooses corporate venturing for recruitment/retention purposes, in an attempt to internalize the impact of spillovers on its main business. 


\subsection{Impact of Competition for Talent}

Competition for talent and its interaction with returns to venturing in the organizational choice are central features of our analysis. As a benchmark, suppose that the firm does not face competition for the star manager (e.g. there is no VC interested in her), and can recruit her as long as it pays her at least some reservation payoff $U_{0}=0 .{ }^{17}$ The expected net payoff to the firm (which successfully recruits the star for all $\Pi \geq \Pi_{\min }$ ), depends on whether it is organized as a corporation or for corporate venturing, and is written $P_{C 0}^{*}=M-U_{0}=M$ or $P_{C V 0}^{*}=\Pi+\frac{\pi^{2}}{4 k}+M^{-}+S$, respectively. ${ }^{18}$ Clearly the relative attractiveness of corporate venturing in the absence of competition, $\Delta P_{0}^{*}=\Pi+\frac{\pi^{2}}{4 k}-$ $\left[M-\left(M^{-}+S\right)\right]$, is increasing in $\Pi$, and one can easily verify that there exists a threshold level $\widetilde{\Pi}_{0}>\Pi_{\text {min }}$ such that organizing as a corporation is optimal for all $\Pi \in\left[\Pi_{\min }, \widetilde{\Pi}_{0}\right)$ and organizing for corporate venturing is optimal for all $\Pi \in\left[\widetilde{\Pi}_{0}, \infty\right)$. The impact of competition for talent on corporate venturing can then be captured as follows:

Proposition 6 Competition for talent has a positive impact on the prevalence of corporate venturing. The threshold level of return to venturing at which the firm switches to corporate venturing is lower in presence of competition for talent than in its absence: $\widetilde{\Pi}<\widetilde{\Pi}_{0}$. Hence, for all $\Pi \in\left[\widetilde{\Pi}, \widetilde{\Pi}_{0}\right)$, competition for talent prompts the firm to engage in corporate venturing, when it would otherwise organize as a corporation.

The intuition for this result is simple. Absent competition from the VC, both the incentives benefit and the recruitment/retention benefit associated with corporate venturing disappear, and the firm only switches to corporate venturing at $\widetilde{\Pi}_{0}$, where the gravy train benefit $\Pi$ (together with the expected marginal benefit from hitting a "home run," $\frac{\pi^{2}}{4 k}$ ) exactly offsets the opportunity cost of not employing the star in the main business, $\left[M-\left(M^{-}+S\right)\right]$.

Competition from the VC prompts the firm to react in several ways. In region $A_{1}$, it increases the star's compensation whether the firm is organized as a corporation or for corporate venturing, with zero net effect on $\Delta P_{1}^{*}$; but under corporate venturing it has the additional effect of increasing the power of incentives. This leads to higher effort, yielding an incentives benefit like the one mentioned above. In region $A_{2}$, competition for talent creates a recruiting problem for the corporation, and corporate venturing is the solution to that problem: It enables the firm to successfully recruit a star

\footnotetext{
${ }^{17}$ The subscript 0 refers to the case where there is zero competition. We normalize $U_{0}$ to zero for simplicity only.

${ }^{18}$ These expressions are obtained by substituting $W_{C 1}^{*}=0$ into $(12)$, and $U_{V C s}=U_{0}=0$ into $P_{C V}^{r}\left(U_{V C s}\right)$, on the left-hand side of (15), respectively.
} 
who would otherwise accept the VC's offer, and to internalize the differential impact of new venture spillovers on its main business.

Thus whether $\widetilde{\Pi}_{0}$ is located in region $A_{1}$ or $A_{2}$, the marginal firm, which is indifferent between the two organizational forms absent competition at $\widetilde{\Pi}_{0}$, would strictly prefer corporate venturing in a competitive market for talent, in an attempt to capture either incentives benefits, or recruitment/retention benefits. The implication, then is that $\widetilde{\Pi}<\widetilde{\Pi}_{0}$ : Competition for talent strictly increases the prevalence of corporate venturing over $\left[\widetilde{\Pi}, \widetilde{\Pi}_{0}\right)$.

\subsection{Impact of Spillovers}

Spillovers also have an impact on the firm's optimal organizational form. Indeed, at the switching threshold level of returns to venturing $\widetilde{\Pi} \in A_{1}$ the surplus created with corporate venturing increases with $S$, while the payoff when organizing as a corporation is not affected.

Proposition 7 Spillovers $S$ increase the relative attractiveness of corporate venturing and, hence, decrease the threshold level of returns to venturing $\widetilde{\Pi}$ beyond which corporate venturing is the optimal organizational form.

As in Hellmann (2002), when products of the new venture and the main line of business are complements, which is captured by $S>0$ in our model, the new venture is developed with corporate venturing. In contrast, when the two products are substitutes $(S<0)$, the new venture is developed by a VC, or via syndication. Thus both in his model and in ours, complementarity between new venture products and main business products favors corporate venturing.

Interestingly, in contrast to his model, here corporate venturing may still be optimal even if $S$ is negative. Important for this result is the fact that even when the new venture has a very negative impact on the main business, corporate venturing may still be optimal if it prevents the $\mathrm{VC}$ from recruiting the star and starting the venture, in which case the impact on the main business would be even worse, by an amount $\delta$. (Another difference with his model is that here spillovers are not restricted to product-market complementarity or substitutability, and may take a more general form. See discussion in section 8.) 


\section{Control Rights Allocation and the Different Types of Corporate Venturing}

Corporate venturing is a general expression that is typically used to describe all types of investments made by corporations into new ventures that are distinct from their core business. In practice, however, corporate venturing investments can take many forms. At one end of the spectrum is the "internal venture": The parent company invests in a new ventures that is legally part of the organization, even if somewhat independent from the main line of business. At the other end of the spectrum is "corporate venture capital": The parent company invests in an external start-up company, through a "captive" fund (Hellmann, 2002), of which the corporate parent acts as a general partner. The key difference between the various types of corporate venturing is the allocation of control rights over the idea/venture: In internal ventures, the allocation of control, and hence bargaining power, is clearly tilted in favor of the parent company, but the relative allocation of control becomes more favorable to the star in setups closer to corporate venture capital.

In our model where payoffs are contractible, all agency problems are addressed using payoffcontingent contracts, and there is no scope for discussion of property/control rights allocation. Regardless of who owns the intellectual property - be it the firm or the star- the two parties are bound by the verifiable contract signed at date 1 , and there is no scope for renegotiation, ex post bargaining and the like. Contracts are complete. As we have shown throughout the paper, this complete contracting approach yields interesting and tractable results. In this extension we depart from this framework and introduce contractual incompleteness by assuming that part of the realized payoff from the new venture is not contractible at date 1 . Introducing contractual incompleteness is interesting for two reasons. The first one is realism: New ventures are typically very uncertain, with the nature of the innovation difficult to describe, and contracts are likely to be incomplete. The second reason is that it generates scope for discussion of the optimal allocation of property/control rights and of the different types of corporate venturing.

To make this framework comparable to our base complete contracting model, we assume that the "home run" marginal payoff $\pi$ is not contractible, while the base payoff $\Pi$ is. The initial contract at date 1 therefore specifies only a payoff $\gamma \leq \Pi$ to be paid to star at date 4 , and the remaining payoff $\Pi-\gamma$ to the firm. The contract may also specify the relative allocation of control/property rights over the idea, $\lambda$. The variable $\lambda$ may for example represent the fraction of the realized payoff that 
the star can obtain (or the probability that she would successfully replicating the venture elsewhere) if bargaining breaks down, while the firm gets $(1-\lambda)$. The marginal payoff $\pi$ is bargained over at date 4 if it is realized. Assuming Nash-like bargaining, the fraction $f$ of $\pi$ extracted by the star will depend on both negotiating parties' relative threat points at that time, which in turn depend on $\lambda$. In the example just given, Nash bargaining implies $f(\lambda)=\lambda .{ }^{19}$ Then the problem with incomplete contracting becomes exactly the same as the one in the base case, simply replacing $\alpha$ by $\gamma$ and $\beta$ by $\lambda$.

Lemma 5 All the key results of the model still hold in an incomplete contracts framework. The main difference comes from the interpretation of the source of incentives for the star. In the complete contracting scenario, it was the result of explicit profit sharing contracted at date 1. In this incomplete contracting scenario, it comes from control rights assigned at date 1, and the associated bargaining power at date 4 .

An interesting consequence of this exercise is that, since in the complete contracting base model $\beta$ (weakly) increases with returns to venturing under corporate venturing (see lemma ??), the implication in the context of incomplete contracting and the various types of corporate venturing is the following:

Proposition 8 In the presence of competition for talent, when corporate venturing is optimal, the firm allocates control rights differently depending on returns to venturing: as returns to venturing increase, more control rights are allocated to the star, gradually switching from types of venturing that are closer to internal ventures, to ones that resemble more corporate venture capital.

The foregoing results shed light on how the interaction between returns to venturing and competition for talent affects the endogenous allocation of control rights between the CV firm and the star, and the different types of corporate venturing. In contrast, other authors, including Anand et al. (2004), and Hellmann (2006), have examined the way changes in the exogenous allocation of intellectual property (IP) rights affect corporate venturing. Interestingly, our model could also be extended to address this issue. Suppose that neither $\Pi$ nor $\pi$ are contractible at date $0,{ }^{20}$ and that the star and the firm or VC bargain over realized payoff at date 4. Consider two IP regimes. In the entrepreneur-friendly regime, the star owns the idea and can costlessly replicate the new venture somewhere else if bargaining breaks down. Assuming Nash Bargaining for example, the star extracts

\footnotetext{
${ }^{19}$ For a thorough discussion on analogies beween complete and incomplete contracts settings, see Tirole (1999).

${ }^{20}$ The same results obtain if, as before, $\Pi$ is contractible.
} 
all rents in renegotiation at date 4 . In the firm/VC-friendly regime, the firm or the VC (depending on whom the star chose) owns the idea, and extracts all rents at date $4 .^{21}$

In the firm/VC-friendly regime, the intuition is very similar to that of our main model, but with zero effort from the the star, since she anticipates that all rents will be extracted by her employer. In that case, the gravy train and recruitment/retention effects are still present and there still exists a threshold level of returns to venturing such that corporate venturing is optimal beyond that threshold.

In the entrepreneur-friendly regime, if the venture were financed, the star would have first-best incentives, since she anticipates extracting all rents. However, for the same reason the VC expects a zero return and does not compete for the star. The firm, will obtain a payoff $M^{-}+S$ if organized for corporate venturing, and $M$ if organized as a corporation. By regularity condition $1, M>M^{-}+S$, and hence the firm organizes as a corporation in equilibrium. The key implication, then, is that while in entrepreneur-friendly regimes yield higher entrepreneurial effort and higher success probability in ventures that are financed, they generate less corporate venturing and new venture creation than firm/VC-friendly regimes. This result is consistent with Anand et al. (2004), and contrasts with Hellmann (2006) where corporate venturing (intrapreneurship) is more prevalent in entrepreneurfriendly IP regimes.

\section{Other Applications and Extensions}

\subsection{Competition, Efficiency, and Economic Activity}

Corporate venturing is socially optimal if and only if the total surplus generated in the first-best (net

of effort cost), $\Pi+\frac{\pi^{2}}{2 k}+M^{-}+S$, is higher than both $i$ ) the total surplus that could be created by allocating the star manager to the competitor, i.e. $\Pi+\frac{\pi^{2}}{2 k}$ from the venture plus $M^{-}+S-\delta$ from the main line of business, and ii) the total surplus that could be generated when organizing the firm as a corporation, $M$.

$$
\Pi+\frac{\pi^{2}}{2 k}+M^{-}+S \geq \Pi+\frac{\pi^{2}}{2 k}+M^{-}+S-\delta,
$$

and

$$
\Pi+\frac{\pi^{2}}{2 k}+M^{-}+S \geq M
$$

\footnotetext{
${ }^{21}$ Alternatively, we could interpret the entrepreneur-friendly regime as one in which the entrepreneur benefits from strong IP protection, and the firm/VC-friendly regime as one in which IP protection for the entrepreneur is weak. This intepretation is more closely related to Anton and Yao (1995), and Anand et al. (2004).
} 
Condition (20) reduces very simply to $-\delta \leq 0$, which always holds in our model; and inequality (21) holds if and only if $\Pi \geq \Pi^{F B}$ with $\Pi^{F B}=\left[M-\left(M^{-}+S\right)\right]-\frac{\pi^{2}}{2 k}$. Thus, corporate venturing is socially optimal for all $\Pi \geq \Pi^{F B}$. The following result then obtains:

Proposition 9 In equilibrium there is less corporate venturing than is socially optimal: $\widetilde{\Pi}>\Pi^{F B}$. Competition for talent simultaneously increases the prevalence of corporate venturing and improves economic efficiency.

This inefficiency is due to agency costs in corporate venturing. When effort is not directly contractible, the firm has to leave rents to the star to induce her to exert a high effort level, and this usually leads to a second-best effort level from the star. This agency cost constrains the rents captured by the firm if it engages in corporate venturing, and induces firms to switch to corporate venturing "too late" relative to the social optimum: for all $\Pi \in\left[\Pi^{F B}, \widetilde{\Pi}\right)$, the firm chooses to remain organized as a corporation even though from a social point of view it ought to organize for corporate venturing.

This inefficiency is even larger absent competition for talent, since as shown in Proposition 6, in that case the firm switches to corporate venturing "even later," at $\widetilde{\Pi}_{0}>\widetilde{\Pi}$. As discussed in subsection 5.2, competition for talent increases equilibrium compensation for the star, and under corporate venturing leads to higher-powered incentives and higher effort exertion. This simultaneously improves the relative attractiveness of corporate venturing and its prevalence in the $\left[\widetilde{\Pi}_{0}, \widetilde{\Pi}\right)$ region, and economic efficiency.

\subsection{Spillovers}

So far we have assumed that spillovers affect only the firm's main line of business, and that the VC receives no spillovers on other ventures in its portfolio. This assumption was made both for simplicity, and to yield starker results. In this Subsection we generalize the model to allow the VC's other projects to benefit from spillovers from the new venture. ${ }^{22}$ The following results can readily be shown:

Proposition 10 In the more general model where the $V C$ also enjoys a spillover $S_{V C}$ if it recruits the star, and $S_{V C}-\delta_{V C}$ if she is not, all results remains unchanged as long as $\delta_{V C} \leq \delta$, i.e. as long as the spillover differential is higher for the firm than for the $V C$. If $\delta_{V C}>\delta$, then for all $\Pi \in A_{1}$ the firm chooses to organize as a corporation rather than for corporate venturing, and for all $\Pi \in A_{2}$, the firm is indifferent between the two organizational forms.

\footnotetext{
${ }^{22}$ This is consistent with Lindsey (2002), who finds evidence of a keiretsu effect in venture capital, suggesting that VCs do benefit from spillovers by facilitating collaborations between their portfolio ventures.
} 
As long as $\delta_{V C} \leq \delta$, if organized for corporate venturing the firm has a higher incentive to recruit the star than the VC; and therefore, as before, it recruits the star under this organizational form. On the other hand, if $\delta_{V C}>\delta$, the $\mathrm{VC}$ benefits more from recruiting the star, and it recruits the star whenever the firm is organized for corporate venturing. Hence, organizing as a corporation is optimal when it yields a higher payoff than not recruiting, i.e. in region $A_{1}$. In region $A_{2}$, the firm cannot recruit the star regardless of its organizational form, and is therefore indifferent between the two. ${ }^{23}$

\section{Empirical Implications}

Our model yields a number of empirical predictions that can improve our understanding of corporate venturing in general, and of its structure in particular. Beyond corporate venturing, it also points to a potential link between labor market competition and firm productivity. In what follows we discuss these predictions and their relation to the empirical literature.

\section{Determinants of Corporate Venturing Investments}

A key contribution of our model is to shed light on the reasons why firms engage in corporate venturing activities, and we identify three key explanations. The gravy train rationale simply states that firms engage in corporate venturing in an attempt to capture some the high returns returns they observe in new ventures, and therefore suggests that higher venturing returns should increase $\mathrm{CV}$ investments.

The incentives rationale captures the idea that as the star's reservation payoff (the compensation she expects to obtain in the labor market) increases, firms respond by offering higher-powered incentives ${ }^{24}$ this induces stars to exert more effort, and increases the relative attractiveness of venturing activities where the star's marginal product of effort is higher. This increase in the star's market compensation may come from higher returns to venturing, which prompt employers to "bid" higher to recruit star managers. Alternatively, it may come from a rise in the degree of competition for

\footnotetext{
${ }^{23}$ Another possible extension is to take into account the state-contingent nature of spillovers. For instance, product market competition or complementarities may vary with the success of the venture. Alternatively, a successful venture may provide a technological breakthrough that will help the main business, while a failed venture may be a relatively cheap way of testing an uncertain technology. Or the relationship between the star and the firm may provide the former with a rehiring rent in case of failure. The most interesting aspect of state-contingent spillovers is that they may enhance incentives if they are "procyclical," or instead lead to the traditional tradeoff between incentives or insurance if they are "counter-cyclical." They would likely affect the balance between the firm and the VC through their relative magnitude and through this incentives effect only.

${ }^{24}$ This is consistent with findings by Core and Guay (2001) and Oyer and Schaefer (2005), who document the positive relation between firms' use of stock options plans (i.e. high-powered incentives) and the degree of competition in the labor market.
} 
talent, for a given level of venturing returns. For example, the shortage of talent may vary across industries/sectors and across time, generating variation in the intensity of competition to recruit stars. Thus the incentives rationale suggests that both higher venturing returns and stronger competition for talent should increase CV investments.

Finally, the recruitment/retention suggests that firms may engage in corporate venturing in an attempt to successfully recruit stars who would otherwise take employment elsewere. ${ }^{25}$ This explanation is echoed by the Corporate Venturing Journal, which stated that: "One of the reasons for corporate venturing is to attract and retain employees who have the right skills and mindset to operate effectively in the new economy [...]." (September 2000, Issue 3). Firms' concern about failing to recruit or retain star managers is stronger when these stars have access to higher levels of market compensation, which again could result from high levels of venturing returns or from strong competition for talent. Corporate venturing investments should therefore increase in both of these situations.

Thus, our three rationales point to two primary factors that will likely affect corporate venturing investments:

Prediction 1: Higher returns to venturing should increase corporate venturing investments.

Prediction 2: Stronger competition for talent should increase corporate venturing investment.

Prediction 1 is consistent with the pro-cyclicality of CV with entrepreneurial activity to which we referred in the introduction to motivate the model, and with the literature, which identifies financial returns as primary determinants of corporate venturing (Siegel, Siegel and MacMillan, 1988; Winter and Murfin, 1988, Chesbrough, 2002). This prediction is also broadly consistent with with Dushnitsky and Lenox (2005b), who find that greater technological opportunities - which are presumably associated with higher expected returns to venturing - have a positive impact on corporate venturing. They report that a large fraction $(79 \%)$ of corporate venture capital funds is invested in sectors in the top quartile in terms of technological opportunities.

Prediction 2 is more novel, and may stimulate future empirical research. To that end, one could proxy competition for talent - which in our model arises from the presence of a VC competing with

\footnotetext{
${ }^{25}$ Losing employees was a real problem for firms at the peak of the entrepreneurial boom in the late 1990s, as noted in Computer World:

"Thirty-two percent of traditional U.S. firms have lost employees to dot-coms, according to a survey of 3,400 executives conducted by BrilliantPeople.com, the online recruiting site of Managements Recruiters International Inc. in Cleveland. In New England, $51.7 \%$ of firms reported employee losses to internet firms. On the West Coast, $44.8 \%$ of firms reported losing employees to startups, followed by the Middle Atlantic region, with $42.7 \%$. The Midwest and South Central regions had the lowest employee losses, with $78.2 \%$ and $86.8 \%$ respectively, saying they haven't lost employees." (September 4, 2000, p.56, business news section)."
} 
the firm for the recruitment of a star manager - with measures of labor mobility for example. Indeed, Fallick, Fleischmann and Rebitzer (2006) find higher job mobility in the Silicon Valley's computer industry than in computer clusters elsewhere, and a natural application of our model would be to relate variation in job mobility to variation in corporate venturing investments. Another possible proxy for labor market competition would be the geographic proximity of firms to centres of venture capital activity: firms closely located to the Silicon Valley, for instance, would likely face stronger competition for talent from local venture capitalists and startups. Finally, temporal and industry variations in the university wage premium (i.e. the difference in wage between university graduates and high-school graduates) may also adequately capture variations in the degree of competition for talent. Using these measure of competition for talent to examine its impact on corporate venturing investment would - it seems - be fruitful.

Our analysis also suggests that corporate venturing investments may be affected by two other factors. One such factor is spillovers, broadly defined as any (positive or negative) impact of the new venture on the main business.

Prediction 3: Greater spillovers from the new venture to the main business should increase corporate venturing investments.

Spillovers are sometimes grouped under the more generic name of "strategic factors" in the corporate venturing literature. Block and MacMillan (1993), and Chesbrough (2002) report that these strategic factors play an important role in the decision to pursue corporate venturing activities. In the US for example, $76 \%$ of corporate venturing firms pursue these activities for strategic purposes (Block and MacMillan, 1993).

Spillovers could be interpreted in several ways. For example, they could be technology spillovers, allowing the firm to gain access to a new technology for the main business; knowledge spillovers, enabling the firm to improve its expertise; or product-market spillovers such as complementarity/substitutability between the new venture product and main business product. ${ }^{26}$ All three types of spillovers have been

\footnotetext{
${ }^{26}$ Spillovers may also come from the labor market, or the financial market. On the labor side, establishing a record of corporate venturing may help the firm to motivate its existing employees, and attact new talent, in the main line of business. Moreover, the firm and the manager of the new venture will learn about one another through corporate venturing, and the firm may have a strategic advantage in reallocating the star to a task that fits both her expertise and her tastes, after "harvesting" the new venture. In other words, the firm may benefit from a rehiring rent. On the financing side, projects developed through corporate venturing can help in the financing of future projects associated with the main line of business. They may also be negatively correlated to the main line of business and trigger spillovers in terms of tax deductions or a decrease in expected bankruptcy costs. Hellmann, Lindsey and Puri (2004) document financial spillovers in Banking, showing that banks target their venture capital investments to firms that may subsequently use their lending services.
} 
identified in the empirical literature as having an impact on CV. Siegel et al. (1988) identify "exposure to new technologies and markets" as a key objective for CV firms, while Winters and Murfin (1988) underline how corporate venturing may enable firms to gain a "window on new technology/business." Dushnitsky and Lenox (2005b) document the impact of knowledge spillovers, reporting that "the more closely aligned the domains of expertise of the firm and a particular sector, the greater the likelihood that the firm will invest in [corporate venturing] in that sector." Finally, Dushnitsky and Shaver (2006) find that the greater the complementarity between the products of the corporate parent and those of the entrepreneur, the greater the likelihood of a corporate venturing relationship to form.

Our model also predicts that the strength of intellectual property (IP) protection for the inventor should have an impact on CV. Corporate venturing should be more prevalent when IP protection is weaker, because in such cases investors (in the form of firms or VCs) anticipate reaping rewards from the new venture, and are more willing to finance ventures in the first place.

Prediction 4: Weaker IP protection for the inventor should increase corporate venturing investments.

This prediction is consistent with recent empirical work on corporate venturing and its connection to IP protection. Dushnitsky and Lenox (2005b), for instance, derive a measure of the effectiveness of patents in protecting inventors' profits, and find that the weaker the IP protection for the inventor (i.e. the lower the effectiveness of these patents), the higher the prevalence of corporate venturing. They also show that weaker IP protection may improve the innovation rate in firms engaged in corporate venturing (Dushnitsky and Lenox, 2005a).

\section{Structure of Corporate Venturing}

The literature on corporate venturing suggests that it may be structured in many ways, differing mainly in the degree of autonomy of the new venture from the corporate parent (Rind, 1981; Roberts and Berry, 1985; Bleicher and Paul, 1987; Gompers, 2002). Our model captures this idea explicitly: The structure of corporate venturing is defined in terms of relative control rights allocation and hence in terms of the star autonomy from the corporate parent. Moreover, prior work suggests that the key advantage of autonomy in the structure of CV is improved innovative activity (Fast, 1981, Sykes, 1986; Russell, 1995; Thornhill and Amit, 2000). This is also consistent with our model where more autonomy in the form of control rights increases the star's ex post bargaining power and hence her ex ante incentives to exert effort. On the other hand, a tighter relationship between the new venture and the corporate parent may enable the new venture to take advantage of the parent's core competencies 
(Dougherty, 1995).

Dushnitsky and Shaver (2006) argue that the degree of autonomy of the new venture might facilitate the formation of corporate venturing activities, by alleviating the star/entrepreneur's concerns about imitation/expropriation by the corporate parent; and find empirical support for this hypothesis. But what exogenous factors might affect the optimal choice of corporate venturing structure? Our model suggests that returns to venturing may play a role in that regard. It predicts that as returns to venturing increase, more autonomy (i.e. control rights) should be allocated to the star, and the organization of corporate venturing should gradually switch from a structure closer to internal ventures, to one that resemble more corporate venture capital:

Prediction 5: Higher returns to venturing should affect the organization of corporate venturing activities, leading to structures where the new venture gradually becomes more independent from the corporate parent.

\section{Beyond Corporate Venturing: Competition for Talent and Productivity}

Finally, the model allows us to make a more general prediction about the connection between labor market competition and firm productivity:

Prediction 6: Competition for talent should increase firm productivity.

Competition for talent, through its positive impact on equilibrium compensation and the power of incentives, may lead to increased managerial effort towards the first-best, thus generating productivity gains. Investigating this link empirically would be the logical next step, and in our opinion a promising avenue for future research. ${ }^{27}$

\section{Conclusion}

A natural explanation for corporate venturing and its pro-cyclicality with returns to entrepreneurship is that firms engage in corporate venturing in an attempt to capture a share of these returns when they are high. This "gravy train" effect may explain the positive impact of venturing returns on corporate venturing. This seems unlikely to be the only explanation, however. The lower returns associated with CV investments, relative to independent VC investments returns (Fast, 1981; Zahra, 1996; Gompers and Lerner, 1998, Gompers, 2002), suggest that investments through traditional venture funds would likely be a better way to scoop the "gravy."

\footnotetext{
${ }^{27}$ Finding evidence confirming this prediction would also corroborate prediction 2, as in our model the increase in productivity is associated with increased corporate venturing.
} 
In this paper we propose two novel explanations for corporate venturing and its pro-cyclical fluctuations with entrepreneurial activity. We argue that firms may engage in corporate venturing activities also to benefit from the superior managerial incentives in new ventures, and to recruit or retain key talent. A important insight to emerge from our analysis is that competition for talent is a key factor in determining corporate venturing investments. This and the other testable predictions of the model suggest several fruitful avenues for future empirical research.

\section{A Appendix: Characterization of the VC's Optimal Contract}

The IC and the IR constraints respectively reduce to:

$$
\begin{aligned}
\beta & =\frac{k e}{\pi}>0, \\
\alpha+e^{2} \frac{k}{2} & >U_{C} .
\end{aligned}
$$

Replacing $\beta$ in the objective function (5), we can re-write the VC's program as follows:

$$
\max _{e, \alpha} \Pi+e \pi-\alpha-k e^{2}
$$

subject to (23) and $\alpha \geq 0$. Solving (24) for $e$, we obtain $e_{V C}^{r}\left(U_{C}\right)=\frac{\pi}{2 k}$ which implies $\beta_{V C}^{r}\left(U_{C}\right)=$ $\frac{k e}{\pi}=\frac{1}{2}$. Hence:

When $U_{C} \in\left[0, \frac{\pi^{2}}{8 k}\right),(23)$ and (8) hold with $e=e_{V C}^{r}\left(U_{C}\right)=\frac{\pi}{2 k}$ and $\alpha=0$. Hence $\left\{e_{V C}^{r}, \alpha_{V C}^{r}, \beta_{V C}^{r}\right\}\left(U_{C}\right)=$ $\left\{\frac{\pi}{2 k}, 0, \frac{1}{2}\right\}$.

When $U_{C} \in\left[\frac{\pi^{2}}{8 k}, \frac{\pi^{2}}{2 k}\right),(23)$ no longer holds with $\left\{e_{V C}^{r}, \alpha_{V C}^{r}, \beta_{V C}^{r}\right\}\left(U_{C}\right)=\left\{\frac{\pi}{2 k}, 0, \frac{1}{2}\right\}$. This is solved by increasing effort along with $U_{C}$, so that $\frac{k}{2} e^{2}=U_{C}$ or $e_{V C}^{r}\left(U_{C}\right)=\sqrt{\frac{2}{k} U_{C}}$; and by setting $\beta_{V C}^{r}\left(U_{C}\right)=\frac{k e}{\pi}=\frac{\sqrt{2 k U_{C}}}{\pi}$ and $\alpha_{V C}^{r}\left(U_{C}\right)=\varepsilon$, with $\varepsilon \rightarrow 0$.

When $U_{C} \in\left[\frac{\pi^{2}}{2 k}, \infty\right)$, keeping $e=\sqrt{\frac{2}{k}\left(U_{C}-\varepsilon\right)}$ would generate an effort level that would be (inefficiently) higher than $e^{F B}$. Instead the VC elicits $e_{V C}^{r}\left(U_{C}\right)=e^{F A_{2}}=\frac{\pi}{k}$ by setting $\alpha_{V C}^{r}\left(U_{C}\right)=$ $U_{C}+\varepsilon-\frac{\pi^{2}}{2 k}$ and $\beta_{V C}^{r}\left(U_{C}\right)=1$, so that the IC, IR, and LL constraints all hold.

The star's and the VC's expected payoffs when the VC recruits the star, $U_{V C}^{r}\left(U_{C}\right)=W_{V C}^{r}\left(U_{C}\right)-$ $c\left(e_{V C}^{r}\left(U_{C}\right)\right)$ and $P_{V C}^{r}\left(U_{C}\right)=\Pi+e_{V C}^{r}\left(U_{C}\right) \pi-W_{V C}^{r}\left(U_{C}\right)$ are described in (10). If the VC does not intend to recruit the star it offers any $\left\{\alpha_{V C}^{n r}\left(U_{C}\right), \beta_{V C}^{n r}\left(U_{C}\right)\right\}$ such that $U_{V C}\left(\alpha_{V C}^{n r}, \beta_{V C}^{n r}\right) \in\left[0, U_{C}\right)$. As 
long as $U_{V C}^{n r}\left(\alpha_{V C}^{n r}, \beta_{V C}^{n r}\right)<U_{C}$, the star chooses the corporation's offer, and the VC receives a payoff $P_{V C}^{n r}=0$.

We define $\bar{U}_{C}$ as the threshold RP to the star (from the corporation) such that the VC is indifferent between recruiting or not: $P_{V C}^{r}\left(\bar{U}_{C}\right)=P_{V C}^{n r}$, which is expressed more precisely in (11). Regularity condition (2) ensures that, for any given $\Pi \geq \Pi_{\min }, P_{V C}^{r}\left(U_{C}\right)=\Pi+\frac{\pi^{2}}{4 k}>0$ for all $U_{C} \in\left[0, \frac{\pi^{2}}{8 k}\right)$. Since $P_{V C}^{r}\left(U_{C}\right)$ is continuous over $\mathbb{R}^{+}$and strictly decreasing in $U_{C}$ over $\left[\frac{\pi^{2}}{8 k}, \infty\right)$, and since $P_{V C}^{r}(\infty)=-\infty$, there must exist a unique $\bar{U}_{C} \geq \frac{\pi^{2}}{8 k}$ defined as in (11), such that it is optimal for the VC to recruit if and only if $U_{C}<\bar{U}_{C} \cdot{ }^{28}$

\section{References}

[1] Amador, M., and A. Landier, 2004, "Entrepreneurial Pressure and Innovation," mimeo Chicago Graduate School of Business.

[2] Anand, B., A. Galetovic, and A. Stein, 2004, "Incentives versus Synergies in Markets for Talent," mimeo Harvard Business School, Universidad de Chile.

[3] Anton, J., and D. Yao, 1995, "Start-ups, Spin-offs, and Internal Projects," Journal of Law, Economics, and Organization, 11, 362-378.

[4] Bleicher, K., and H. Paul, 1987, "The External Corporate Venture Capital Fund - A Valuable Vehicle for Growth," Long Range Planning, 20, 64-70.

[5] Block, Z., and I. MacMillan, 1993, Corporate Venturing: Creating New Businesses with the Firm, Harvard Business School Press.

[6] Brander, J., and J.-E. de Bettignies, 2006, "Venture Capital Consentration and Dynamics: A Role for Path Dependence," working paper, University of British Columbia.

[7] Chemla, G., M. Habib, and A. Ljungqvist, 2005, "An Analysis of Shareholder Agreements," Journal of the European Economic Association, forthcoming.

[8] Chesbrough, H., 2002, "Making Sense of Corporate Venture Capital," Harvard Business Review, 4-11.

[9] Core, J., and W. Guay, 2001, "Stock Options for Non-Executive Employees," Journal of Financial Economics, 61, 253-287.

[10] Dix, M., and N. Gandelman, 2003, "R\&D Institutional Arrangements: Start-up Ventures Versus Internal Lab," mimeo Tulane University, Universidad ORT.

[11] Dougherty, D., 1995, "Managing Your Core Incompetencies for Corporate Venturing," Entrepreneurship Theory and Practice, 113-135.

\footnotetext{
${ }^{28}$ If regularity condition (2) does not hold, there are two possibilities. If $\Pi_{\min } \leq-\frac{\pi^{2}}{4 k}$, then: i) for all $\Pi \in\left[\Pi_{\min },-\frac{\pi^{2}}{4 k}\right)$ there exists no value of $\bar{U}_{C}$ such that $P_{V C}^{r}\left(\bar{U}_{C}\right)=0$; and $\left.i i\right)$ for $\Pi=-\frac{\pi^{2}}{4 k}$ there exists an infinite number of values of $\bar{U}_{C}<\frac{\pi^{2}}{8 k}$ such that this is the case. If $\Pi_{\min }>-\frac{\pi^{2}}{4 k}+\varepsilon$, there are no changes to the model.
} 
[12] Dushnitsky, G., and M. Lenox, 2005a, "When Do Incumbents Learn From Entrepreneurial Ventures? Corporate Venture Capital and Investing Firm Innovation Rates," Research Policy, 34, 615-639.

[13] Dushnitsky, G., and J. M. Shaver, 2006, "Limitations to Inter-Organizational Knowledge Acquisition: The Paradox of Corporate Venture Capital" working paper, University of Pennsylvania.

[14] Dushnitsky, G., and M. Lenox, 2005b, "When Do Firms Undertake R\&D By Investing in New Ventures?," Strategic Management Journal, 26, 947-965.

[15] Fallick, B., C. Fleischmann, and J. Rebitzer, 2005, "Job Hopping in the Silicone Valley: Some Evidence Concerning the Micro-Fuoundations of a High Technology Cluster," Review of Economics and Statistics, forthcoming.

[16] Fast, N., 1981, "Pitfalls of Corporate Venturing," Research Management, 24, 21-24.

[17] Goldman, Sachs \& Co, and Frank Russell Company, 2002, Alternative Investing by Tax-Exempt Organizations 2001: A Survey of Organizations in North-America, Europe, Australia, and Japan, Technical Report.

[18] Gompers, P., 2002, "Corporations and the Financing of Innovation: The Corporate Venturing Experience," Federal Reserve Bank of Atlanta Economic Review, 1-17.

[19] Gompers, P., and J. Lerner, 1998, "The Determinants of Corporate Venture Capital Successes: Organizational Structure, Incentives, and Complementarities," National Bureau of Economic Research Working Paper no. 6725.

[20] Gromb, D., and D. Scharstein, 2002, "Entrepreneurship in Equilibrium," mimeo London Business School and MIT Sloan School of Management.

[21] Grossman, S. and O. Hart (1986), "The Costs and Benefits of Ownership: A Theory of Vertical and Lateral Integration," Journal of Political Economy, 94, 691-719.

[22] Hellmann T., 2002, "A Theory of Strategic Venture Investing" Journal of Financial Economics, 64, 285-314.

[23] Hellmann, T., 2006, "When Do Employees Become Entrepreneurs?" Management Science, forthcoming.

[24] Hellmann, T., L. Lindsey, and M. Puri, 2004, "Building Relationships Early: Banks in Venture Capital," working paper, Duke University.

[25] Landier, A., 2003, "Entrepreneurship and the Stigma of Failure," mimeo Chicago Graduate School of Business.

[26] Lazear, E., 2005, "Entrepreneurship," Journal of Labor Economics, 23, 649-680.

[27] Lindsey, L., 2002, "The Venture Capital Keiretsu Effect: An Empirical Analysis of Strategic Alliances Among Portfolio Firms," working paper, Stanford University.

[28] Oyer, P., and S. Schaefer, 2005, "Why Do Some Firms Give Stock Options to All Employees?: An Empirical Examination of Alternative Theories," Journal of Financial Economics, 76, 99-133.

[29] Rind, K., 1981, "The Role of Venture Capital in Corprate Development," Strategic Management Journal, 2, 169-180. 
[30] Roberts, E., and C. Berry, 1985, "Entering New Business: Selecting Strategies for Success," Sloan Management Review, 3-17.

[31] Russell, R., 1995, "An Investigation of Some Organizational Correlates of Corporate Entrepreneurship: Towards a Systems Model of Organizational Innovation," Entrepreneurship, Innovation and Change, 4, 295-314.

[32] Schmidt K., 2003, "Convertible Securities and Venture Capital Finance," Journal of Finance, 1139-66.

[33] Siegel, R., E. Siegel, and I. MacMillan, 1988, "Corporate Venture Capitalists: Autonomy, Obstacles, and Performance," Journal of Business Venturing, 3, 233-247.

[34] Sykes, H, 1986, "The Anatomy of a Corporate Venturing Program: Factors Influencing Success," Journal of Business Venturing, 1, 275-293.

[35] Taylor, J., 2003, "The U.S. Venture Capital Industry in 2002," International Financial Law Review, 22.

[36] Thornhill, S., and R. Amit, 2000, "A Dynamic Perspective on Internal Fit in Corporate Venturing," Journal of Business Venturing, 16, 25-50.

[37] Tirole J., 1999, "Incomplete Contracts: Where Do We Stand?" Econometrica, 67(4), 741-81.

[38] Winters, T., and D. Murfin, 1988, "Venture Capital Investing for Corporate Development Objectives," Journal of Business Venturing, 3, 207-222.

[39] Zahra, S., 1996, "Technology Strategy and New Venture Performance: A Study of CorporateSponsored and Independent Biotechnology Ventures," Journal of Business Venturing, 11, 289-321. 


\title{
Corporate Venturing, Allocation of Talent, and Competition for Star Managers ONLINE SUPPLEMENT
}

\author{
Jean-Etienne de Bettignies and Gilles Chemla
}




\section{Proof of Lemma 1}

It follows directly from the characterization of the optimal contract, and from expression (9) in the text, that the power of incentives $\beta_{V C}^{r}\left(U_{C}\right)$ and equilibrium effort $e_{V C}^{r}\left(U_{C}\right)$ are both weakly increasing functions of $U_{C}$.

\section{Proof of Proposition 1}

Follows directly from the text.

\section{Proof of Lemma 2}

From (11), the derivative $\bar{U}_{C}^{\prime}(\Pi)$ can written using the implicit function theorem:

$$
\frac{d \bar{U}_{C}}{d \Pi}=-\frac{\frac{\partial P_{V C}^{r}}{\partial \Pi}}{\frac{\partial P_{V C}^{r}}{\partial \bar{U}_{C}}} .
$$

We know that $\frac{\partial P_{V C}^{r}}{\partial \Pi}=1>0$. We verify from $(10)$ that $\bar{U}_{C}\left(\Pi_{\min }\right)=\frac{\pi^{2}}{8 k}$, and that $\frac{\partial P_{V C}^{r}}{\partial \bar{U}_{C}}\left[\bar{U}_{C}\left(\Pi_{\min }\right)\right]<$ 0 , which implies $\frac{d \bar{U}_{C}}{d \Pi}\left[\bar{U}_{C}\left(\Pi_{\min }\right)\right]>0$. Since $\frac{\partial P_{V C}^{r}}{\partial \bar{U}_{C}}<0$ for all $\bar{U}_{C} \geq \frac{\pi^{2}}{8 k}$, we obtain $\bar{U}_{C}^{\prime}(\Pi)>0$ for all $\Pi \geq \Pi_{\min }$.

In contrast, $\bar{U}_{V C}=M-\left(M^{-}+S-\delta\right)$ is independent of $\Pi$. From regularity constraint (1) $\bar{U}_{V C}>\frac{\pi^{2}}{8 k}+\varepsilon+\delta>\frac{\pi^{2}}{8 k}=\bar{U}_{C}\left(\Pi_{\min }\right){ }^{1}$ Since $\bar{U}_{C}^{\prime}(\Pi)>0, \bar{U}_{C}$ is continuous at all $\Pi \geq \Pi_{\min }$, and $\bar{U}_{V C}^{\prime}(\Pi)=0$, there must exist a threshold level of return to venturing $\widehat{\Pi}>\Pi_{\min }$ - defined implicitly as the solution to $\bar{U}_{C}(\widehat{\Pi})=\bar{U}_{V C}$ - such that $\bar{U}_{C}(\Pi) \leq \bar{U}_{V C}$ if and only if $\Pi \leq \widehat{\Pi}$. Then the corporation recruits the star if and only if $\bar{U}_{C}(\Pi) \leq \bar{U}_{V C}$, i.e. $\Pi \in\left[\Pi_{\min }, \widehat{\Pi}\right]$. The expression for the expected net payoff $P_{C}^{*}(\Pi)$ can be deduced directly from Proposition 1 .

\section{Proof of Proposition 2}

The payoff to the corporation is clearly expressed in (12), and the impact of returns to venturing on this payoff can be written:

\footnotetext{
${ }^{1}$ If regularity conditions (1) and (2) do not hold, then for some parameter values, a special case may occur where $\bar{U}_{C}(\Pi)>\bar{U}_{V C}$ for all values of $\Pi \in\left[\Pi_{\min }, \infty\right)$. In that less interesting case, the VC recruits the star for all values of $\Pi \in\left[\Pi_{\min }, \infty\right)$.
} 


$$
\frac{d P_{C}^{*}(\Pi)}{d \Pi}=\left\{\begin{array}{ll}
\frac{d P_{C 1}^{*}(\Pi)}{d \Pi}=-\frac{d W_{C 1}^{*}\left(\bar{U}_{C}(\Pi)\right)}{d \Pi}=-\frac{d \bar{U}_{C}(\Pi)}{d \Pi}<0 & \text { for } \Pi \in A_{1} \\
\frac{d P_{C 2}^{*}(\Pi)}{d \Pi}=0 & \text { for } \Pi \in A_{2}
\end{array}\right\} .
$$

\section{$5 \quad$ Proof of Proposition 3}

Follows directly from the text.

\section{Proof of Proposition 4}

Differentiating (16) with respect to $\Pi$ we obtain:

$$
\frac{d P_{C V}^{*}}{d \Pi}=1-\frac{d \bar{U}_{C V}(\Pi)}{d \Pi}+\frac{d\left[e_{C V}^{*}\left(\bar{U}_{C V}(\Pi)\right) \pi-c\left(e_{C V}^{*}\left(\bar{U}_{C V}(\Pi)\right)\right)\right]}{d \Pi}
$$

The direct effect is represented by the number one on the right-hand side (RHS) of (A3). The "compensation cost" effect is captured by the second term on the RHS of (A3). A proof identical to that of Lemma 2 shows that this effect is negative. Finally, the third term on the RHS of (A3) reflects the positive "managerial incentives" effect. Using the proofs of Lemmas 1 and 2, this effect is easily shown to be positive.

To see that $P_{C V}^{*}=M^{-}+S+\varepsilon$ is independent of $\Pi$, recall that by definition, $\bar{U}_{C V}$ satisfies:

$$
P_{V C s}^{r}\left(\bar{U}_{C V}\right)=\Pi+e_{V C s}^{r}\left(\bar{U}_{C V}\right) \pi-W_{V C s}^{r}\left(\bar{U}_{C V}\right)=0 .
$$

This can be rewritten as:

$$
\Pi-\bar{U}_{C V}+\left[e_{V C s}^{r}\left(\bar{U}_{C V}\right) \pi-c\left(e_{V C s}^{r}\left(\bar{U}_{C V}\right)\right)\right]=\varepsilon .
$$

Since the CV firm and the VC make the same offer and elicit the same effort, i.e. $e_{V C s}^{r}()=$. $e_{C V}^{r}()=.e_{C V}^{*}\left(\bar{U}_{C V}\right)$, we can substitute (A5) into (16) and obtain $P_{C V}^{*}=\left[M^{-}+S\right]+\varepsilon$, with $\varepsilon \rightarrow 0$. Accordingly, the negative compensation cost effect of $\Pi$ exactly offsets the positive direct effect and managerial incentives effect: $\frac{d P_{C V}^{*}}{d \Pi}=1-\frac{d W_{C V}^{*}}{d \Pi}+\frac{d e_{C V}^{r}}{d \Pi} \pi=0$. 


\section{Proof of Lemma 3}

The firm recruits the star under both organizational forms. The star's payoff is the same under both organizational structures $\left(\bar{U}_{C V}(\Pi)=\bar{U}_{C}(\Pi)\right)$, and therefore cancels out of $\Delta P_{1}^{*}$. Equation (18) then obtains from (10) and (16). Differentiating (18) with respect to $\Pi$ yields:

$$
\frac{d\left(\Delta P_{1}^{*}\right)}{d \Pi}=1+\frac{d\left[e_{C V}^{*}\left(\bar{U}_{C V}(\Pi)\right) \pi-c\left(e_{C V}^{*}\left(\bar{U}_{C V}(\Pi)\right)\right)\right]}{d \Pi}>1
$$

\section{Proof of Lemma 4}

Follows directly from the text.

\section{$9 \quad$ Proof of Proposition 5}

It is sufficient to prove the existence of $\widetilde{\Pi}$. Like $P_{C V}^{*}(\Pi)$ and $P_{C}^{*}(\Pi), \Delta P^{*}(\Pi)$ is a continuous function of $\Pi$ over $A_{1} \cup A_{2}$. Moreover, (1) and (2) imply that $\Delta P^{*}\left(\Pi_{\min }\right)<0$, and from Lemmas 3 and 4 , $\Delta P^{*}(\Pi)$ is strictly increasing over $\left[\Pi_{\min }, \widehat{\Pi}\right]$, and constant and positive over $(\widehat{\Pi}, \infty) \cdot{ }^{2}$ Hence, there exists a threshold level $\widetilde{\Pi} \in\left(\Pi_{\min }, \widehat{\Pi}\right]$ such that $\Delta P^{*}(\Pi) \geq 0$ (in which case corporate venturing is optimal) if and only if $\Pi \in[\widetilde{\Pi}, \infty)$.

\section{Proof of Proposition 6}

From the text we know that $P_{C V 0}^{*}=\Pi+\frac{\pi^{2}}{4 k}+\left(M^{-}+S\right)$ and $P_{C 0}^{*}=M$. Therefore the relative attractiveness of corporate venturing in the absence of competition can be written:

$$
\Delta P_{0}^{*}=P_{C V 0}^{*}-P_{C 0}^{*}=\Pi+\frac{\pi^{2}}{4 k}-\left[M-\left(M^{-}+S\right)\right]
$$

Since a) $\Delta P_{0}^{*}(\Pi)$ is continuous over $\left[\Pi_{\min }, \infty\right)$, b) $\Delta P_{0}^{*}\left(\Pi_{\min }\right)=\varepsilon-\left[M-\left(M^{-}+S\right)\right]<0$ (from regularity condition $(1))$, and c) $\frac{d\left(\Delta P_{0}^{*}\right)}{d \Pi}=1$ over $\left[\Pi_{\min }, \infty\right)$, there must exist a threshold level $\widetilde{\Pi}_{0}>$ $\Pi_{\min }$ such that $\Delta P_{0}^{*}(\Pi) \geq 0$ if and only if $\Pi \in\left[\widetilde{\Pi}_{0}, \infty\right)$.

\footnotetext{
${ }^{2}$ If regularity conditions (1) and (2) do not hold, then for some parameter values, a special case may occur where $\Delta P^{*}(\Pi) \geq 0$ for all values of $\Pi \in\left[\Pi_{\min }, \infty\right)$. In that less interesting case, corporate venturing is always optimal.
} 
The effect of competition on the relative attractiveness of corporate venturing can be written:

$$
\Delta P_{1}^{*}-\Delta P_{0}^{*}=\left[e_{C V}^{*}\left(\bar{U}_{C V}(\Pi)\right) \pi-c\left(e_{C V}^{*}\left(\bar{U}_{C V}(\Pi)\right)\right)\right]-\frac{\pi^{2}}{4 k}
$$

From the proof of Lemma 2 we know that $\bar{U}_{C V}\left(\Pi_{\min }\right)=\bar{U}_{C}\left(\Pi_{\min }\right)=\frac{\pi^{2}}{8 k}$. Using $(9)$, we obtain $\Delta P_{1}^{*}\left(\Pi_{\min }\right)-\Delta P_{0}^{*}\left(\Pi_{\min }\right)=\frac{\pi^{2}}{8 k}>0$.

From the proof of Lemma $2, \bar{U}_{C V}^{\prime}(\Pi)>0$ for all $\Pi \geq \Pi_{\min }$. Hence $\bar{U}_{C V}(\Pi)>\frac{\pi^{2}}{8 k}$, for all $\Pi>\Pi_{\text {min }}$. Since $e_{C V}^{*}\left(\bar{U}_{C V}(\Pi)\right)=e_{C V}^{r}\left(\bar{U}_{C V}(\Pi)\right)$ in $A_{1}$, we know from (9) that $e_{C V}^{*}\left(\bar{U}_{C V}(\Pi)\right) \pi-$ $c\left(e_{C V}^{*}\left(\bar{U}_{C V}(\Pi)\right)\right)$ is weakly increasing in $\bar{U}_{C V}$ for all $\bar{U}_{C V}(\Pi)>\frac{\pi^{2}}{8 k}$, and weakly increasing in $\Pi$ for all $\Pi>\Pi_{\min }$. Therefore so is $\Delta P_{1}^{*}-\Delta P_{0}^{*}$.

Hence, $\Delta P_{1}^{*}-\Delta P_{0}^{*}>0$ for all $\Pi \in A_{1}$. In particular $\Delta P_{0}^{*}(\widetilde{\Pi})<\Delta P_{1}^{*}(\widetilde{\Pi})=0$. This implies that $\Delta P_{0}^{*}$ switches from negative to positive at a threshold level $\widetilde{\Pi}_{0}>\widetilde{\Pi}$.

\section{Proof of Proposition 7}

From (18), the relative attractiveness of corporate venturing in region $A_{1}$ at the threshold level $\widetilde{\Pi}$ can be written:

$$
\Delta P_{1}^{*}(\widetilde{\Pi})=\widetilde{\Pi}+\left[e_{C V}^{*}\left(\bar{U}_{C V}(\widetilde{\Pi})\right) \pi-c\left(e_{C V}^{*}\left(\bar{U}_{C V}(\widetilde{\Pi})\right)\right)\right]-\left[M-\left(M^{-}+S\right)\right]=0 .
$$

Using the implicit function theorem, we can write:

$$
\frac{d \widetilde{\Pi}}{d S}=-\frac{\frac{\partial \Delta P_{1}^{*}}{\partial S}}{\frac{\partial \Delta P_{1}^{*}}{\partial \widetilde{\Pi}}} .
$$

From the proof of Proposition $6, e_{C V}^{*}\left(\bar{U}_{C V}(\widetilde{\Pi})\right) \pi-c\left(e_{C V}^{*}\left(\bar{U}_{C V}(\widetilde{\Pi})\right)\right)$ is weakly increasing in $\widetilde{\Pi}$. Hence, $\widetilde{\Pi}+\left[e_{C V}^{*}\left(\bar{U}_{C V}(\widetilde{\Pi})\right) \pi-c\left(e_{C V}^{*}\left(\bar{U}_{C V}(\widetilde{\Pi})\right)\right)\right]$ strictly increases with $\widetilde{\Pi}$, and hence $\frac{\partial \Delta P_{1}^{*}}{\partial \widetilde{\Pi}}>0$. Since $\frac{\partial \Delta P_{1}^{*}}{\partial S}>0$, this implies that $\frac{d \widetilde{\Pi}}{d S}<0$.

\section{Proof of Lemma 5}

Suppose that $\pi$ is not contractible, while $\Pi$ is. The initial contract at date 1 therefore specifies only a payoff $\gamma \leq \Pi$ to be paid to star at date 4 , and the remaining payoff $\Pi-\gamma$ to the firm. The contract may also specify the relative allocation of control/property rights over the idea, $\lambda$. The variable $\lambda$ 
represents the fraction of the realized payoff that the star can obtain (or the probability that she would successfully replicating the venture elsewhere) if bargaining breaks down, while the firm gets $(1-\lambda)$. The marginal payoff $\pi$ is bargained over at date 4 if it is realized. Assuming Nash bargaining, the star will give a transfer $t$ to the firm, such that $t \in \arg \max (\pi-t-\lambda \pi)(t-(1-\lambda) \pi)$. This yields $t=(1-\lambda) \pi$ leaving the star with $\pi-t=\lambda \pi$, and the firm with $t=(1-\lambda) \pi$.

Thus, the firm chooses $\gamma$ and $\lambda$ to maximize $\Pi+e \pi-(\gamma+e \lambda \pi)$, in exactly the same way as it chose $\alpha$ and $\beta$, respectively, in our base model. Then the problem with incomplete contracting becomes exactly the same as the one in the base case, simply replacing $\alpha$ by $\gamma$ and $\beta$ by $\lambda$.

\section{Proof of Proposition 8}

Follows directly from the text.

\section{Proof of Proposition 9}

We have shown in the text that corporate venturing is optimal from a social point of view if $\Pi \geq \Pi^{F B}$, with

$$
\Pi^{F B}=M-\left(M^{-}+S\right)-\frac{\pi^{2}}{2 k}
$$

In contrast, the firm's switching threshold level $\widetilde{\Pi}$ satisfies (A9). We need only show that $\widetilde{\Pi}>\Pi^{F B}$.

For all $\Pi \in\left[\Pi^{F B}, \widetilde{\Pi}\right)$, the firm choose to remain organized as a corporation even though from a social point of view it ought to organize for corporate venturing.

If $\Pi^{F B}<\Pi_{\min }=-\frac{\pi^{2}}{4 k}+\varepsilon$, then $\widetilde{\Pi}>\Pi_{\min }>\Pi^{F B}$, and the prevalence of corporate venturing is too low: For all $\Pi \in\left[\Pi_{\min }, \widetilde{\Pi}\right)$ socially desirable corporate venturing does not take place.

If parameter values are such that $\Pi^{F B} \geq \Pi_{\min }$, we need only show that $\Delta P_{1}^{*}\left(\Pi^{F B}\right) \leq 0$. Using (18) and (A11), we can write:

$$
\Delta P_{1}^{*}\left(\Pi^{F B}\right)=\left[e_{C V}^{*}\left(\bar{U}_{C V}\left(\Pi^{F B}\right)\right) \pi-c\left(e_{C V}^{*}\left(\bar{U}_{C V}\left(\Pi^{F B}\right)\right)\right)\right]-\frac{\pi^{2}}{2 k} .
$$

Since, for all $\Pi \geq \Pi_{\min }, \bar{U}_{C V}(\Pi) \geq \frac{\pi^{2}}{8 k}$, we have $\bar{U}_{C V}\left(\Pi^{F B}\right) \geq \frac{\pi^{2}}{8 k}$, for all $\Pi^{F B} \geq \Pi_{\min }$. From (9),

$$
\frac{3 \pi^{2}}{8 k} \leq\left[e_{C V}^{*}\left(\bar{U}_{C V}\right) \pi-c\left(e_{C V}^{*}\left(\bar{U}_{C V}\right)\right)\right] \leq \frac{\pi^{2}}{2 k}
$$


for all $\bar{U}_{C V} \geq \frac{\pi^{2}}{8 k}$. This implies that $\Delta P_{1}^{*}\left(\Pi^{F B}\right) \leq 0$ for all $\Pi^{F B} \geq \Pi_{\min }$.

The proof that competition for talent simultaneously increases the prevalence of corporate venturing and improves economic efficiency follows directly from the text.

\section{Proof of Proposition 10}

Assume that the VC enjoys spillovers from the new venture to its other portfolio ventures. These spillovers take on value $S_{V C}$ if the new venture is developed by the $\mathrm{VC}$, and $S_{V C}-\delta_{V C}$ if it is developed by the firm. Then:

1. If the firm is organized as a corporation, the threshold $\mathrm{RP} \bar{U}_{C}$ faced by the $\mathrm{VC}$ is now slightly higher, reflecting the impact of the VC's spillover differential $\delta_{V C}$ on its surplus from recruitment. Equation (11) must thus be replaced by:

$$
\Pi+e_{V C}^{r}\left(\bar{U}_{C}\right) \pi-W_{V C}^{r}\left(\bar{U}_{C}\right)=-\delta_{V C} .
$$

In turn the higher value of $\bar{U}_{C}$ implies a lower value of $\widehat{\Pi}$, the threshold level of returns to venturing beyond which the $\mathrm{VC}$, rather than the corporation, recruits the star.

2a If the firm is organized for corporate venturing, its threshold $\mathrm{RP} \bar{U}_{V C}$ remains unchanged, implicitly defined as in (15). It follows directly that, if $\delta \geq \delta_{V C}$, the firm can always recruit the star if organized for corporate venturing. Our qualitative results are as above, even though the key thresholds $\widetilde{\Pi}$ and $\widehat{\Pi}$ might be different.

2b If on the other hand, $\delta<\delta_{V C}$, then the $\mathrm{VC}$, rather than the firm, recruits the star when the firm is organized for corporate venturing. The firm receives $M^{-}+S-\delta$ if $i$ ) it organizes for corporate venturing, or ii)) it organizes as a corporation and $\Pi>\widehat{\Pi}$. Therefore, the firm organizes as a corporation for all $\Pi \in\left[\Pi_{\min }, \widehat{\Pi}\right]$, and is indifferent between organizational forms $C$ and $C V$ for all $\Pi \in(\widehat{\Pi}, \infty)$ (in which case we have assumed it chooses corporate venturing). 